Research Article

\title{
Internal Structure of a Jet Nozzle for Coalbed Methane Mining Based on Airfoil Curves
}

\author{
Jian Chen $\left(\mathbb{D},{ }^{1}\right.$ Liwen Guo $\left(\mathbb{D},{ }^{2}\right.$ Yanwei Hu $\mathbb{D},{ }^{1}$ and Yong Chen ${ }^{3}$ \\ ${ }^{1}$ College of Mining and Safety Engineering, Shandong University of Science and Technology, Qingdao 266590, China \\ ${ }^{2}$ North China University of Science and Technology, TangShan 063609, China \\ ${ }^{3}$ CNOOC Ener Tech-Drilling and Production Co., Tianjin 300461, China \\ Correspondence should be addressed to Liwen Guo; guoliwen@ncst.edu.cn
}

Received 18 August 2018; Accepted 16 October 2018; Published 2 December 2018

Academic Editor: Francesco S. Marulo

Copyright (C) 2018 Jian Chen et al. This is an open access article distributed under the Creative Commons Attribution License, which permits unrestricted use, distribution, and reproduction in any medium, provided the original work is properly cited.

Based on airfoil curves that can effectively balance the rectification and drag reduction effects in flight hydrodynamics, we designed an internal streamline structure of jet nozzle for coalbed methane (CBM) mining. The three types of nozzles originating from three typical airfoil curves are compared with the conical nozzle. Results showed that the thin-type streamlined nozzle had the largest effective shock range and least radial divergence and was thus selected as the best nozzle. Moreover, the pressure distribution at the outlet of the nozzle was found to be related to the range and number of small-pressure fluctuations near the wall. A larger number of small-pressure fluctuations and a larger range caused faster pressure of the jet water column to decay along the axial direction. Rectification with a concentrated effect also slowed down the attenuation velocity of the jet-watercolumn pressure between the concentration point and the nozzle. The variation rule of shock pressure with range was further determined experimentally. We found that the shock pressure of jet water column initially increased within a short distance and then decreased rapidly. The effective shock range of the thin-type streamlined nozzle in air was 1.417 times that of the conical nozzle, and the effective reaming area was 1.104 times greater. Thus, the effect of reaming was effectively improved. The length of the water column at high pressure was larger than that of the conical nozzle, and the shock efficiency was relatively high.

\section{Introduction}

As an important unconventional energy source, coalbed methane (CBM) plays an important role in the global energy structure $[1,2]$. China's CBM reserves rank third in the world, and industrial exploitation of CBM is gradually being promoted $[3,4]$. In China, the main reservoirs of CBM have the characteristics of deep burial, low gas permeability, high ground stress, and high gas pressure. These are the main factors that constrain the development of China's CBM mining industry. Coal seam water injection fracturing technology is a traditional method for enhanced permeability mining of CBM [5]. This technology greatly improves the development range of coal seam fissures and expands the CBM extraction radius. However, this technology is suitable for hard coal seams and is not effective for soft coal seams. The wetting of the coal seam water will cause tiny cracks to be blocked by the water body. This condition can cause airway blockage in coal seams where the fracturing effect is not ideal. This process is not conducive to the discharge of CBM. In China, part of the CBM production process is achieved by extraction drilling holes that are formed by shocking of water jet [6]. These water-jet drilling holes have the characteristics of small outer mouth and large inner cavity. The pressure relief caused by high-pressure water-jet punching and enhanced permeability technology can realize deep punching, directional reaming, controllable hole contour, and airways not being blocked by the water body. During the punching process, the shock pressure of the jet water column acts on the coal body to break it, and then the high-pressure water peels off, carries, and discharges the broken coal block, thereby forming a hole. The surrounding rock mass is unstable and destroyed. The high-pressure scouring during the shock process will cause shock disturbance, thereby further promoting the development of cracks around the coal and rock mass, and discharging the CBM by pressure relief is achieved. 
Subsequent CBM extraction occurs. In this process, the effect of shock coal breaking is mainly determined by the shock pressure of the jet water column, and the shock-pressure relief effect is mainly affected by the pore size of the pressure relief hole formed by the shock. However, because of the current use of conical nozzles with simple design, convenient processing, and low manufacturing cost for punching, the jet water column diverges and atomizes seriously (Figure 1). The effective shock range is short, and a large amount of energy is consumed by air wall resistance. The water column shock pressure cannot easily exert the maximum effect on the coal body, and the expansion effect of the hole is poor. This process has caused problems such as a large workload of coal miners, poor effect of coal seam permeability enhancement, and a waste of water resources. To improve the working efficiency of high-pressure water-jet punching and pressure relief technology, reduce the working time burden of coal miners, improve the operation effect, and increase the safety of underground coalmine production, we must study the problem of divergence, atomization, and short jet distance of the jet stream.

The poor rectification effect and poor drag reduction effect of the internal streamline structure of the nozzle are the main reasons for the problems of jet water column divergence, atomization, and short jet distance. To improve the rectification and drag reduction effect of the internal streamline structure of the nozzle, the structure and parameters of the nozzle of the water-jet equipment currently used for shock crushing have been studied. The pertinent literature is as follows.

Liu et al. [7] studied the coal-breaking law combined with the shock damage of the nozzle and the physical damage of the pick and selected the best-fitting angle between the two, and determined the variation of shock pressure of water jets under different diameters and flow rates based on the SPH smooth particle principle. Schwartzentruber and Papini [8] studied the parameters of the new microabrasive nozzle shock borosilicate glass crushing and perforation, and they then compared the influence of the separation distance, residence time, and pressure of three different caliber nozzles. Lieblich et al. [9] conducted in-depth research on microaperture nozzles. The law of the effective jet of the microaperture nozzle under high Reynolds number fluid is analyzed when the critical capillary length is approximately $70 \%$ of the nozzle diameter. Balamurugan et al. [10] studied parameters such as discharge pressure, separation distance, and injection angle of the nozzle with controllable cavitation degree. The shock residual stress and the distortion of the test piece are most likely to occur when the spray angle is $45^{\circ}$. Li et al. [11] analyzed the variation of the shock pressure of the jet water column in the nozzle that has different degrees of uneven structure at the exit and determined that the chamber length is ideal in submerged (the optimum chamber to diameter ratio $L / d_{1}=3$ ) or in air (the optimum chamber to diameter ratio $L / d_{1}=2$ ). Schwartzentruber et al. [12] established the transient fluid-structure interaction model of the nozzle, determined the fluid domain of the numerical model, and analyzed the influence of different nozzle sizes on the shock pressure. NIE [13] conducted numerical simulation of the flow field inside and outside the high-pressure abrasive water-jet nozzle. The nozzle diameter was determined proportional to the jet pressure and inversely proportional to the inlet pressure. Li et al. [14] studied the relationship between the cone size and the shock pressure of a highvelocity self-oscillating pulse jet nozzle to determine the ability of the regional discontinuity to enhance the peak. Fujisawa et al. [15] studied the cavitation mechanism of the cavitation nozzle jet. The shock wave originated in the near-wall region. Peng et al. [16] used numerical simulation and high-definition cameras to analyze the relationship between the structure of a cavitation jet nozzle and the shape and extent of the jet water column. Pereira et al. [17] designed high-pressure water-jet atomizing nozzles. The divergence and atomization of the fluid is achieved by changing the internal swirling flow path of the water jet. Lin et al. [18] studied the variation law of waterjet cutting pressure and the mechanism of permeability enhancement, and they determined the rectification cutting effect of the cutting nozzle. Momber [19] studied the relationship between the number of nozzles and the shock effect and found that the most effective configuration is characterized by an optimum balance between nozzle number, nozzle diameter, and nozzle orbit for a given stand-off distance.

The above research has been comprehensively studied from a variety of angles such as the nozzle cone angle, nozzle diameter, nozzle length, nozzle exit curve, diffusion angle, nozzle structure and shock medium relationship, nozzle and laser assist, nozzle and pick assist, and nozzle arc chamfer curve rectification effect. These developments have promoted the rapid development of the water-jet field. However, the above research has rarely studied the relationship between the internal streamline structure of the nozzle and the shock pressure and effective shock range. Although some scholars have designed circular chamfers at the exit of the conical nozzle or designed the entire curve as a circular arc, these designs do not completely balance the relationship between rectification and wall resistance and only consider rectification. The parameter of the effective shock range of the nozzle has not been studied. The internal structure curve of the nozzle looks like a simple curve as the wing curve, but it is important in rectifying and adjusting the wall resistance, thereby determines the trajectory of the fluid and is worthy of further study.

To quickly and efficiently realize the rectification and drag reduction of the mine water-jet nozzle, the efficiency of punching must be improved. In this paper, the relationship between the parameters that affects the shock effect, the internal wall resistance of the nozzle, and the rectification effect is analyzed by the principle of fluid mechanics. Based on the airfoil spline curve that can effectively handle the relationship between flow line wall resistance and rectification, three types of internal flow line structure curves with typical characteristics are designed. The CFX module of ANSYS numerical simulation software is used to study the law of velocity and pressure changes of three nozzles after shocking water and compared with the simulation results of ordinary conical 


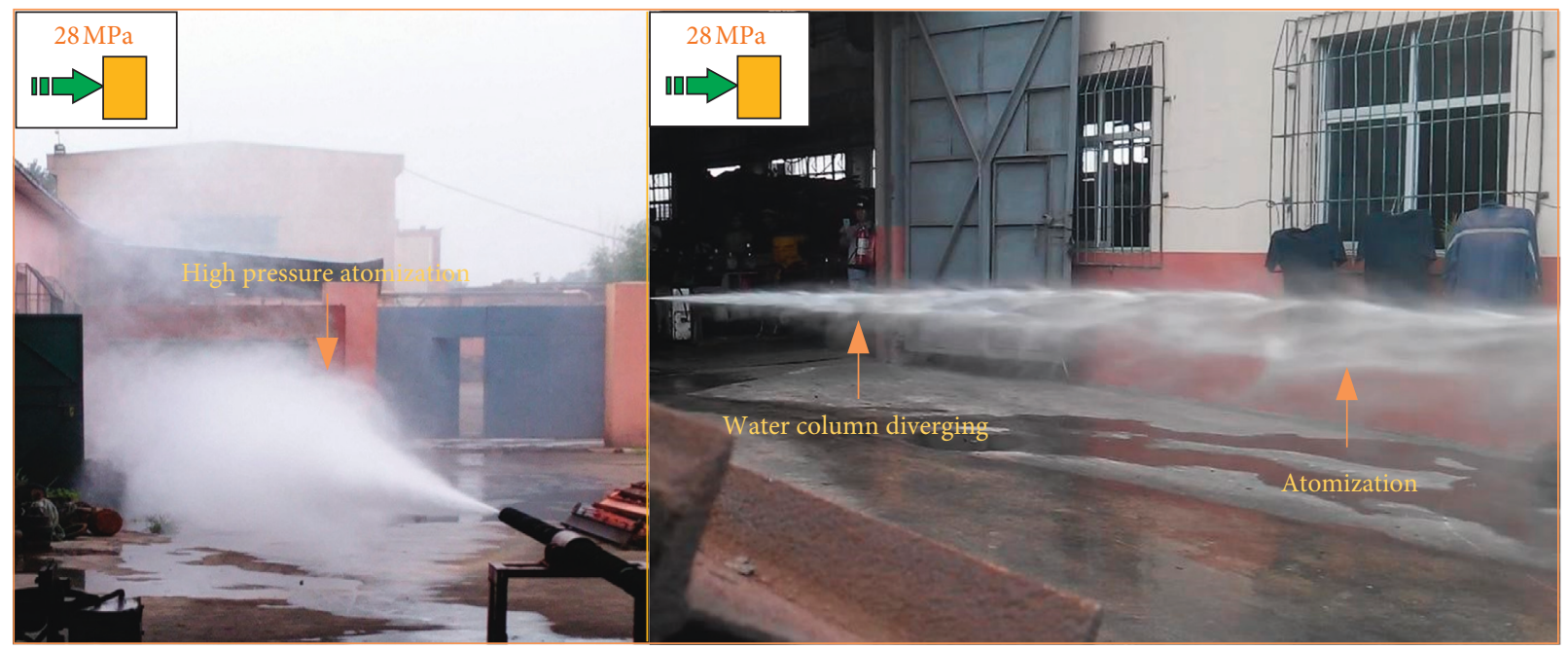

Figure 1: Diagram of divergence atomization of the jet water column in an ordinary conical nozzle.

nozzle. We determine the internal streamline structure curve of the optimal nozzle. A shock-pressure comparison experiment between the optimal nozzle and the ordinary conical nozzle was conducted, and the variation law of the shock pressure of the two nozzles with the range was analyzed. The effective shock range relationship between the two nozzles was further studied, and the working advantage of the optimal nozzle was determined.

\section{Problem Identification and Streamline Design}

2.1. Theoretical Analysis. The cross-sectional view of highpressure water jets in air is as shown in Figure 2, and the water supply pressure of the nozzle inlet is fixed. The highpressure water is rectified into the air through the nozzle, and the water body at the outermost side of the water column entrains the air to form a high-velocity eddy current and atomizes, thereby consuming the energy of the jet water column. As the range increases, this phenomenon gradually erodes into the interior of the water column, thereby causing the jet water column to diverge over a large area. The expression of the jet diameter $R(x)$ from the nozzle outlet $x$ is determined as

$$
R(x)=x \tan \frac{\theta}{2}
$$

High-pressure water-jet shock is a complex hydrodynamic problem. To simplify the analysis, we determined that within a short distance, the water column develops freely after being ejected and is not affected by gravity and frictional wall resistance. Then, the water jet is conserved along the momentum flux:

$$
\int_{A_{1}} \rho u_{1}^{2} d A=\int_{A_{2}} \rho u_{2}^{2} d A=\cdots=\int_{A_{n}} \rho u_{n}^{2} d A=\text { const. }
$$

Assuming that the jet water column is symmetrically distributed, its momentum flux conservation formula can be simplified to

$$
\int_{0}^{R_{1}} \rho u_{\mathrm{y}_{1}}^{2} \cdot 2 \pi y d y=\int_{0}^{R_{2}} \rho u_{\mathrm{y}_{2}}^{2} \cdot 2 \pi y d y=\cdots=\rho u_{0}^{2} \pi R_{0}^{2} .
$$

We conduct dimensionless processing on the above formula to obtain a dimensionless radial distance $\lambda$ :

$$
\lambda=\frac{\mathrm{y}_{\mathrm{m}}}{R_{\mathrm{m}}}
$$

In the above equation, $\mathrm{y}_{m} \in[0,1]$; therefore, $\lambda \in[0,1]$, simultaneous (1), (3), and (4) can be obtained.

$$
\frac{u_{\mathrm{m}}}{u_{0}}=\sqrt{\frac{1}{\pi}} \cdot \frac{1}{\tan \theta / 2} \cdot \frac{R_{0}}{x} .
$$

The velocity attenuation on the central axis of the highpressure water-jet column is the slowest, and the kinetic energy is the greatest. This velocity can best represent the energy change of the jet water column; thus, the equation of velocity variation on the central axis is determined as follows:

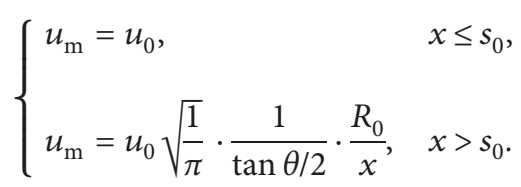

The entire process of fluid flow from the nozzle inlet to the nozzle outlet is analyzed and is known by the conservation of energy:

$$
E\left(u_{\mathrm{c}}\right)=f+E\left(u_{0}\right)
$$

Analysis of Equations (6) and (7) shows that $u_{\mathrm{m}}$ is related to the divergence angle $\theta$ and the internal wall resistance $f$ of the nozzle, and $u_{\mathrm{m}}$ is an important parameter to determine the shock kinetic energy of the jet water column. The magnitude of the shock kinetic energy determines the magnitude of the shock pressure, and the change in the shock kinetic energy affects the effective shock range. Therefore, the jet water column shock pressure and effective shock range are related to the divergence angle $\theta$ and the internal wall resistance of the nozzle $f$. The internal streamline structure of 


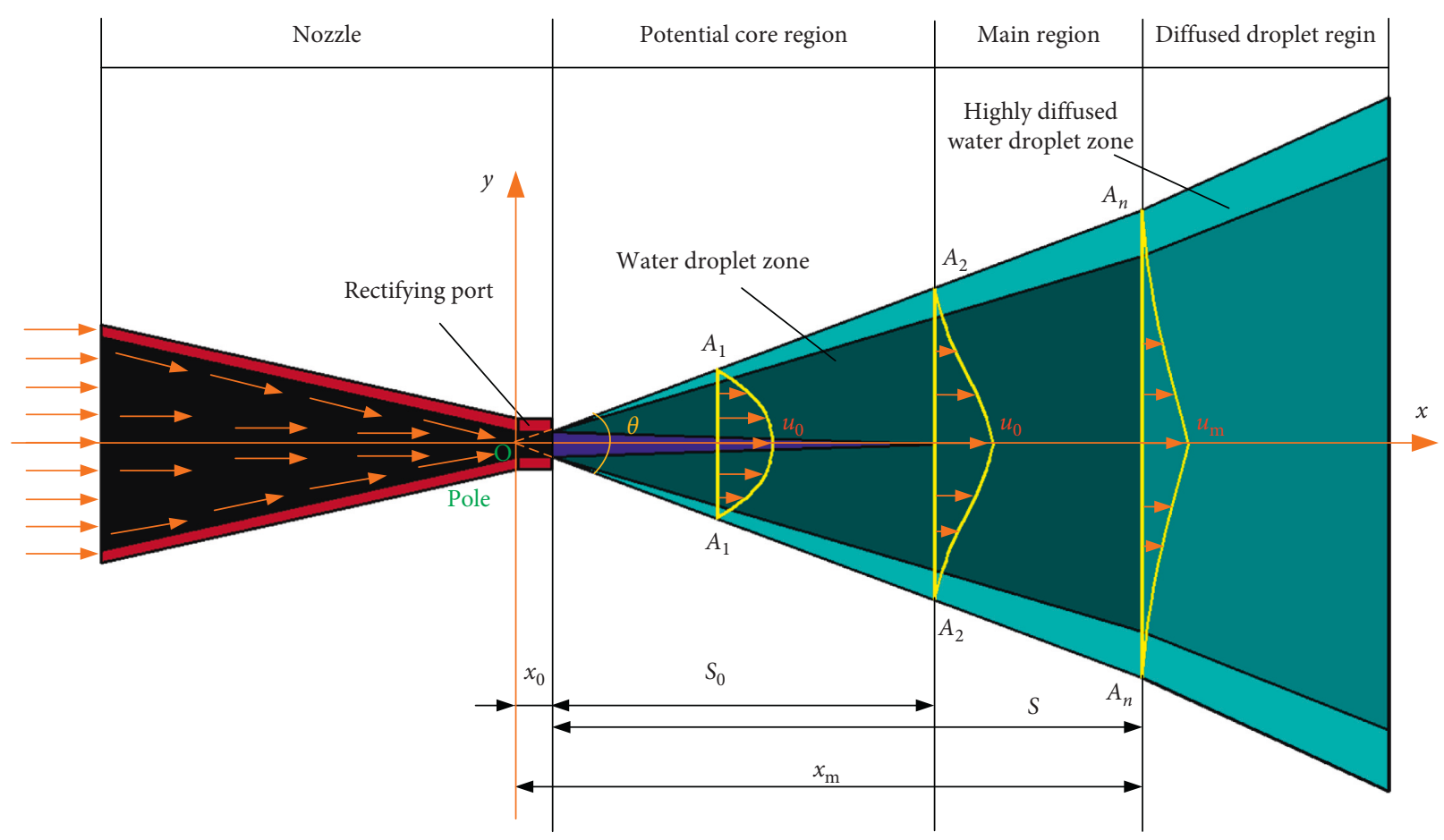

Figure 2: Cross-sectional view of high-pressure water jets in air.

the nozzle is the main factor that affects the divergence angle and the wall resistance. Therefore, optimizing the internal streamline structure of the nozzle, reducing the internal wall resistance, and improving the rectification effect are necessary, thereby increasing the shock pressure and expanding the effective shock range.

2.2. Interior Streamline Design of Nozzle. When designing the internal streamline structure of the nozzle, the two factors of rectification and wall resistance affect each other. Therefore, solving the relationship between the two is a rather complicated process. The internal fluid of the highpressure water-jet nozzle is a high-velocity flow, and the jet velocity at the nozzle is generally above $240 \mathrm{~m} / \mathrm{s}$. The internal structure design process of the nozzle is mainly for drag reduction and rectification by optimizing the streamline structure. The research on the airfoil curve of the aircraft is also aimed at solving the relationship between the drag reduction and rectification, and the flight velocity of the aircraft is close to the internal flow velocity of the highpressure water-jet nozzle. Research on aircraft airfoil curves has the characteristics of large investment, many achievements, and wide research scope. Therefore, selective research is carried out on the basis of aircraft airfoil. The analysis found that the upper surface of the airfoil curve is similar to the inlet fluid condition of the nozzle and is the starting point for large rectification of the high-pressure fluid. The control technology for the wall resistance and flow direction of the airfoil rectifying section is relatively mature. The tail of the airfoil has a better rectification effect and wall resistance control ability, and the flow line from the middle to the tail of the lower part of the tail of the airfoil has a better rectification effect on the high-pressure fluid. These locations are similar in function to the internal streamline structure of the nozzle; these positions are similar to the function of the internal streamline structure of the nozzle, and the airfoil curve is a practically strong curve obtained by fine-tuning the local control points of the airfoil curve by many experiments and empirical analysis on the basis of theoretical design. The NREL $S$ series airfoil in the United States has obvious effects in both the processing wall resistance and the rectification process and has been internationally recognized. Therefore, it is used for reference research. The NREL S series airfoil curve can be represented by the Granville [20] streamline body profile curve analytical optimization function:

$$
\begin{cases}F(x)=H(x) \sqrt{2 x-x^{2}}, & 0 \leq x \leq 1, \\ H(x)=a_{0}+a_{1} x+a_{2} x^{2}+\cdots+a_{n} x^{n}, & n \in N_{+} .\end{cases}
$$

By using the coefficient of the shape function as the design variable, we determine the airfoil shape together with the control point of the reference airfoil and select 12 control point design variables $\mathrm{D}=\left[\mathrm{m}_{1}, \ldots, \mathrm{m}_{12}\right]$ (six parameters on the upper and lower surfaces). We obtain the following airfoil function surface equation:

$$
\left\{\begin{array}{l}
y_{\text {up }}=y_{\text {up } 0}+\sum_{k=1}^{k=6} \mathrm{~m}_{k} F(x), \\
y_{\text {low }}=y_{\text {low } 0}+\sum_{k=1}^{k=6} \mathrm{~m}_{k+6} F(x) .
\end{array}\right.
$$

We select the reference section of the airfoil curve for analysis, determine the important control points $\left(x_{n}, y_{n}\right)$ in the curve, and then scale the control points proportionally based on the nozzle size parameters (nozzle inlet diameter $51 \mathrm{~mm}$, outlet diameter $6 \mathrm{~mm}$, nozzle length $90 \mathrm{~mm}$ ) [21]. 
The relationship between the control points before and after scaling is as follows:

$$
\left(x_{i}, y_{i}\right) \longrightarrow\left(k_{1} x_{i}, k_{2} y_{i}\right)
$$

We determine the control parameters of the starting point coordinates, the end point coordinates, the end position velocity direction, and the control point coordinates. We then obtain the boundary condition function equation

$$
\left\{\begin{array}{l}
F(0)=0 \\
F(0.09)=0.0225 \\
F(0.09)^{\prime}=0 \\
F\left(k_{1} x_{1}\right)=k_{2} y_{1} \\
F\left(k_{1} x_{2}\right)=k_{2} y_{2} \\
\vdots
\end{array}\right.
$$

The simultaneous equations are solved to obtain the function coefficients in the $H(x)$ complex function, and finally the internal streamline curve function of the nozzle is obtained. The entire design process is shown in Figure 3.

In this paper, the NREL $S$ series airfoil curves are selected to represent three typical airfoil curves, S805 A, S804, and S812 airfoils. The three airfoils have different degrees of consideration for rectification and wall resistance, which is consistent with the idea of rectification and drag reduction. Therefore, the upper surface front end of the S805 A airfoil curve, the upper surface front end of the S804 airfoil curve, and the lower surface rear end of the S812 airfoil curve are selected as the basic function curves of the internal flow line structures of the three types of nozzles, respectively. Solving the conditional function equation yields the coefficients in the $H(x)$ complex function. We determine the internal curves of the three nozzles.

$$
\begin{aligned}
F(x)= & \left(-2.060 x^{3}-7.2666 x^{2}+1.07076 x+0.0182605\right) \\
& \cdot \sqrt{2 x-x^{2}}, \\
F(x)= & \left(147.611 x^{3}-34.0262 x^{2}+2.25047 x+0.0197288\right) \\
& \cdot \sqrt{2 x-x^{2}}, \\
F(x)= & \left(-69.947 x^{3}+3.97468 x^{2}+0.818005 x-0.000555912\right) \\
& \cdot \sqrt{2 x-x^{2}} .
\end{aligned}
$$

The nozzle curve is shown in Figure 4, where I is a conical nozzle and is a control group for three newly designed nozzles. The internal structure is a straight line, and the rectifying port is added near the spout of the nozzle. Such a nozzle is easy to process, and the wall resistance and rectification effects are less considered. The inside of nozzle II is a thin-type streamlined curve, which mainly uses the low-curvature spline curve at the front end of the upper surface of the S805 A airfoil to connect the nozzle to the water inlet. The water outlet rectification and streamline smooth transition can be realized. This nozzle design considers the problems of rectification and drag reduction to a certain extent. The inside of nozzle III is a fat streamlined curve, and the sprue water outlet and the water inlet are mainly connected by a high-curvature spline curve at the front end of the upper surface of the S804 airfoil. The nozzle outlet rectification is realized, the arc change rate at the nozzle outlet is reduced, and the rectification length is increased. This nozzle focuses on the rectification effect. The inside of nozzle IV is a double-chamfered streamlined curve that mainly adopts the spline curve of the lower end of the S812 airfoil, and the shrinkage transition is realized at the nozzle inlet and the outlet. The inlet and outlet flow lines are made parallel. The two arcs are connected by a smooth spline curve. This nozzle has more considerations for the inlet wall resistance and considers the rectification of the water outlet. However, the diameter of the middle position shrinks rapidly, the wall resistance increases relatively, and the rectification angle increases the difficulty of rectification.

\section{Model and Simulation Analysis}

In the study of breaking of water-jet shock rock, the model is generally built into a water-jet shock solid to study the shock failure pressure, or the model is built into a jet column into the air field to study the flow of water-jet column. In jet coal breaking, with the increase of shock depth, a deeper shock hole will form in the coal body. Given the high-pressure water-jet pressure relief technology, the water supply pressure is $30 \mathrm{MPa}$, the nozzle caliber is $6 \mathrm{~mm}$, and the shock flow is $20-30 \mathrm{~m}^{3}$. This is a very large amount of water.

When the range is far, with the increase in drainage wall resistance, water is filled between the borehole wall and the nozzle, thereby severely depleting the energy of the jet column and reducing the shock failure capacity of the broken coal water column. Therefore, the analysis of shock failure capacity and shock damage range of different nozzle can be transformed into analysis of shock parameters of jet water columns in the inner water field of borehole. The purpose of the simulation is to select the optimal internal flow line structure of the nozzle, which uses quantitative and qualitative analyses. The high-pressure water was determined to be a continuously incompressible liquid during the analysis. To analyze the internal wall resistance of the nozzle and to realistically reduce the drainage wall resistance of the borehole, the wall resistance of the nozzle and the wall resistance of the borehole will be considered.

In this paper, the CFX module of the fluid simulation software ANSYS is used to simulate the entire process. The whole process ignores heat exchange; thus, solving the energy equation is not needed. When the fluid enters the nozzle at a constant pressure and is sprayed into the borehole filled with water through the nozzle, the following mass conservation equation (continuity equation) is observed throughout the process:

$$
\frac{\partial \rho}{\partial t}+\frac{\partial(\rho u)}{\partial x}+\frac{\partial(\rho v)}{\partial y}+\frac{\partial(\rho w)}{\partial z}=0
$$

In a given microunit, the time rate of change in fluid momentum is equal to the sum of external forces applied on 


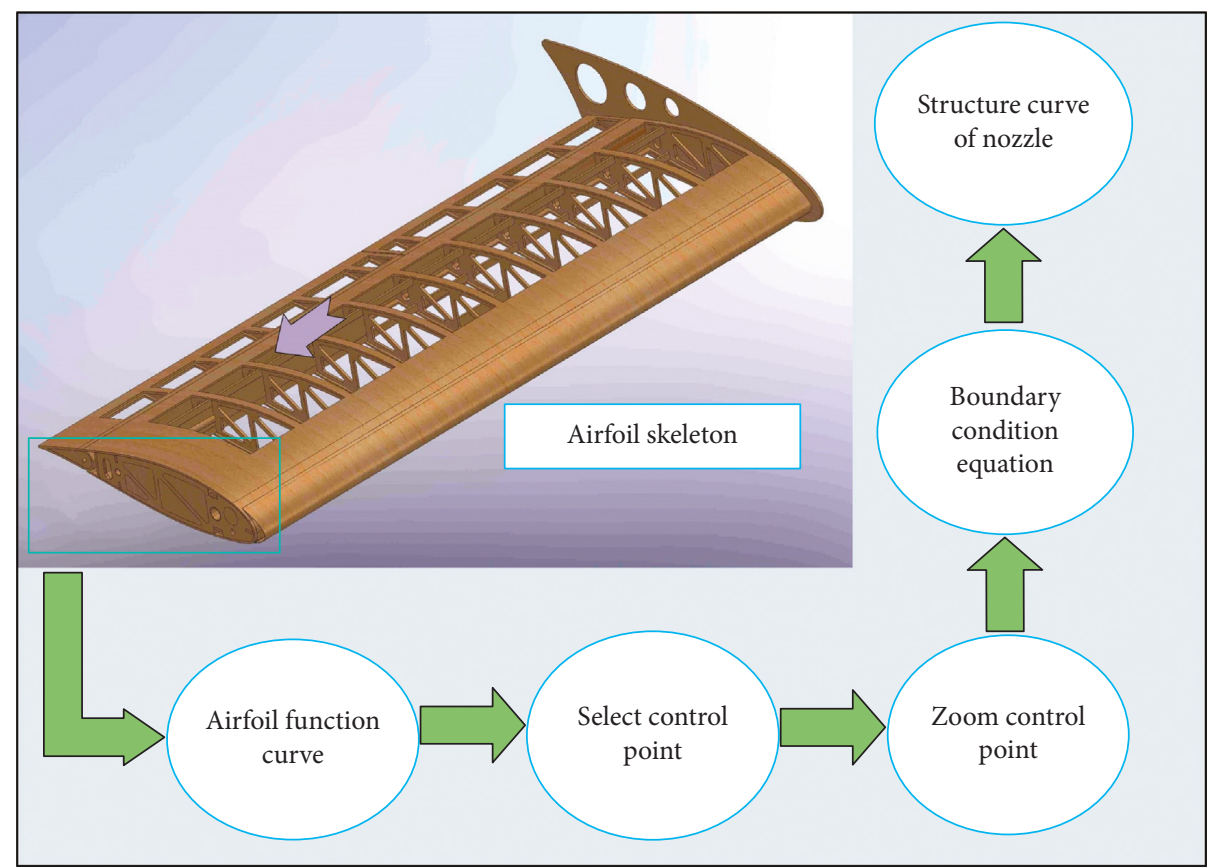

Figure 3: Flow chart of streamline curve design inside nozzle.

it. The momentum conservation equation (also called $N-S$ equation) is expressed by the following mathematical expressions:

$$
\begin{aligned}
\frac{\partial(\rho u u)}{\partial x}+\frac{\partial(\rho u v)}{\partial y}+\frac{\partial(\rho u w)}{\partial z}= & \frac{\partial}{\partial x}\left(u \frac{\partial u}{\partial x}\right)+\frac{\partial}{\partial y}\left(u \frac{\partial u}{\partial y}\right) \\
& +\frac{\partial}{\partial z}\left(u \frac{\partial u}{\partial z}\right)-\frac{\partial p}{\partial x}+S_{\mathrm{u}} \\
\frac{\partial(\rho v u)}{\partial x}+\frac{\partial(\rho v v)}{\partial y}+\frac{\partial(\rho v w)}{\partial z}= & \frac{\partial}{\partial x}\left(u \frac{\partial v}{\partial x}\right)+\frac{\partial}{\partial y}\left(u \frac{\partial v}{\partial y}\right) \\
& +\frac{\partial}{\partial z}\left(u \frac{\partial v}{\partial z}\right)-\frac{\partial p}{\partial y}+S_{\mathrm{v}} \\
\frac{\partial(\rho w u)}{\partial x}+\frac{\partial(\rho w v)}{\partial y}+\frac{\partial(\rho w w)}{\partial z}= & \frac{\partial}{\partial x}\left(u \frac{\partial w}{\partial x}\right)+\frac{\partial}{\partial y}\left(u \frac{\partial w}{\partial y}\right) \\
& +\frac{\partial}{\partial z}\left(u \frac{\partial w}{\partial z}\right)-\frac{\partial p}{\partial y}+S_{\mathrm{w}}
\end{aligned}
$$

The turbulent kinetic energy transport equation is

$$
\begin{aligned}
\frac{\partial(\rho k)}{\partial t}+\frac{\partial\left(\rho u_{i} k\right)}{\partial x_{i}}= & \frac{\partial\left[\left(\mu+\mu_{t} / \sigma_{k}\right) \partial k / \partial x_{j}\right]}{\partial x_{j}}+G_{k}+G_{\mathrm{b}}-\rho \varepsilon \\
& -Y_{\mathrm{M}}+S_{k} .
\end{aligned}
$$

The turbulent kinetic energy dissipation rate transport equation is

$$
\begin{aligned}
\frac{\partial(\rho \varepsilon)}{\partial t}+\frac{\partial\left(\rho u_{i} \varepsilon\right)}{\partial x_{i}}= & \frac{\partial\left[\left(\mu+\mu_{t} / \sigma_{\varepsilon}\right)\left(\partial \varepsilon / \partial x_{j}\right)\right]}{\partial x_{j}} \\
& +C_{1 \varepsilon} \times \frac{\varepsilon}{k}\left(G_{K}+C_{3 \varepsilon} G_{\mathrm{b}}\right)-C_{2 \varepsilon} \rho \frac{\varepsilon^{2}}{k}+S_{\varepsilon}
\end{aligned}
$$
wall is

The fluid velocity function of the near wall of the rough

$$
u^{+}=\frac{1}{K} \ln \left(\frac{y^{*}}{1+0.3\left(y^{R}(\rho / \mu) u^{*}\right)}\right)+C
$$

The model was preprocessed using CFX software. The key parameters for the simulation are shown in Table 1.

Model boundary conditions and local mesh processing are shown in Figure 5. The model is iteratively solved, the solution data are postprocessed using CFD-POST software, and relevant data are extracted for analysis.

The grid independence is analyzed in this paper to determine the influence of grid parameters on the simulation results. This paper mainly studies the divergence rule of water around the sprinkler head and outlet, and so it is divided into smaller meshes. To save computing resources, other locations are divided into larger grids. In the Convergence Criteria, the residual type selects RMS, and the residual target is set to 0.0001 . In order to verify the independence of the mesh, two groups of mesh models with large differences in the mesh numbers and a good mesh quality are compared and analyzed. The two sets of grid parameters are shown in Table 2.

The two sets of calculation results were analyzed. In the analysis, the velocity distribution at the center line is taken as 


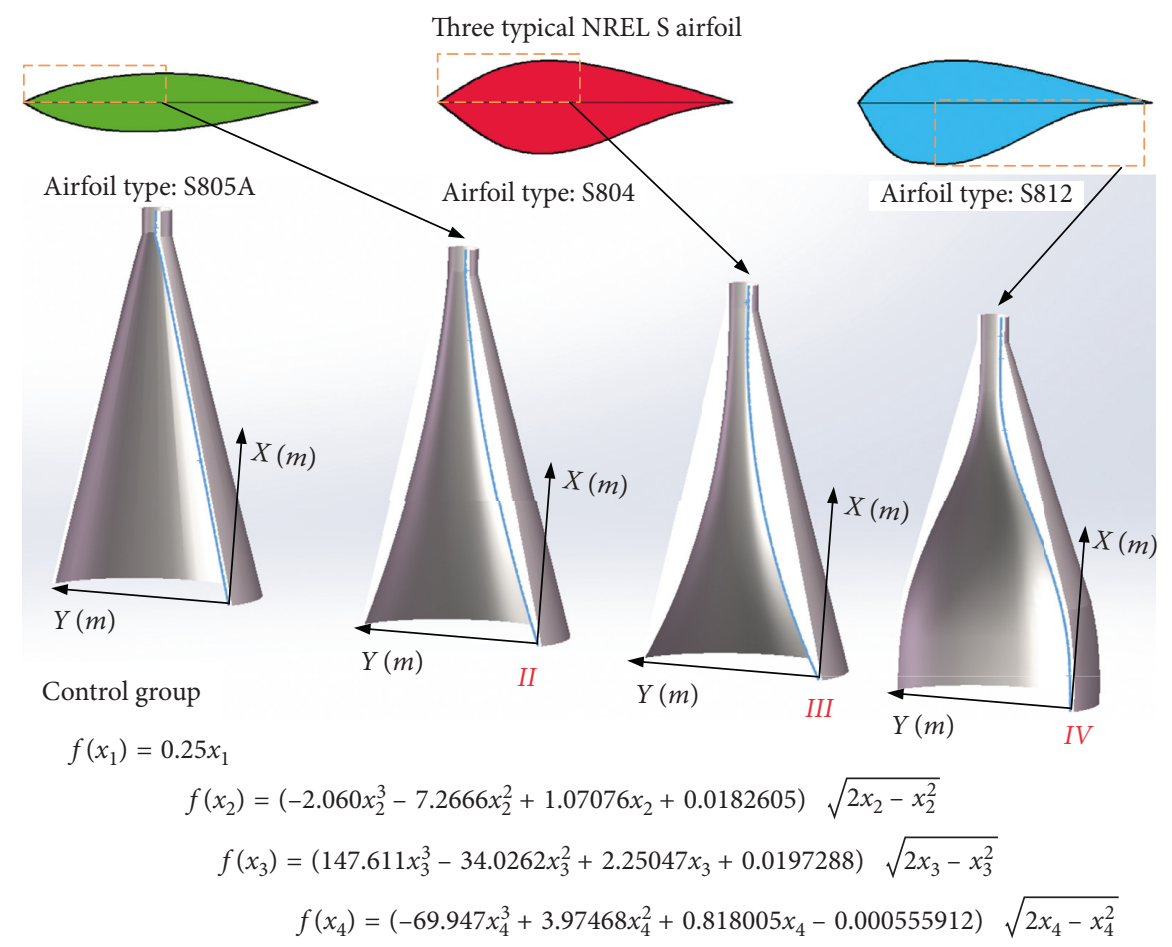

FIgURE 4: Schematic diagram of the inner structure of the nozzle.

TABle 1: Seepage simulation parameter.

\begin{tabular}{lc}
\hline Parameter & Value \\
\hline Simulation type & Steady state simulation \\
Fluid type & Water \\
Turbulence model & K-epsilon \\
Domain type & Single fluid domain \\
Heat transfer model & Isothermal model $\left(25^{\circ} \mathrm{C}\right)$ \\
Time scale & Physical time scale $(100 \mathrm{~s})$ \\
Inlet pressure & $P=30 \mathrm{MPa}$ \\
Outlet pressure & Atmospheric pressure \\
& Nozzle roughness 0.0466 $\mathrm{mm}$ \\
Boundary conditions & Coal-water-jet drilling roughness $10 \mathrm{~mm}$ \\
& Nonsliding wall \\
\hline
\end{tabular}

the analysis index, and the velocity distribution results under two kinds of grid densities are shown in Figure 6.

There is no significant difference between the above results, which shows that the effect of the multiplication of grid density on the calculation results is very small and can be ignored. Therefore, it is possible to exclude the grid's influence on the computation results.

\section{Shock-Pressure Measurement Experiment}

Using numerical control technology, the best nozzle is processed following the structural curve, as shown in Figure 7 . We accurately determine the variation of the shock pressure with the range after the jet water column is ejected. The process can provide a basis for judging the parameters such as the best nozzle shock effect and effective range. Generally, the shock pressure of the jet water column mostly uses a single-point long-term shock measurement analysis.
However, to study the effective range of the jet water column and the shock pressure with the range variation law, the experiment is set to linear motion to measure continuously the shock pressure. This approach can provide a basis for judging the parameters such as the best nozzle shock effect and effective shock range.

After the water column shocks the pressure measuring board, the pressure measuring board transmits the shock pressure to the four springs, and the spring can effectively increase the stability of the energy transmission and reduce the influence of the left and right rigid vibrations on the sensor. The spring transmits the shock pressure to the four pressure sensors. The four pressure sensors convert the pressure signal into an electrical signal and transmit the latter to the signal processor. The signal processor analyses the four sets of data, feeds back the real shock pressure on the pressure measuring board, and transfers these data to the data display for demonstration and storage. In the data-processing analysis, the rolling friction force is considered, and the effective shock contact area is converted on the basis of cross-sectional areas at different positions of the water column. The shock pressure value at different positions of the water column is calculated.

$$
\left\{\begin{array}{l}
p=\frac{F}{S}, \\
F=F_{f}+F, \\
F_{f}=\mu_{f} F_{2}, \\
\mu=f\left(\frac{F_{2}}{C}\right) .
\end{array}\right.
$$




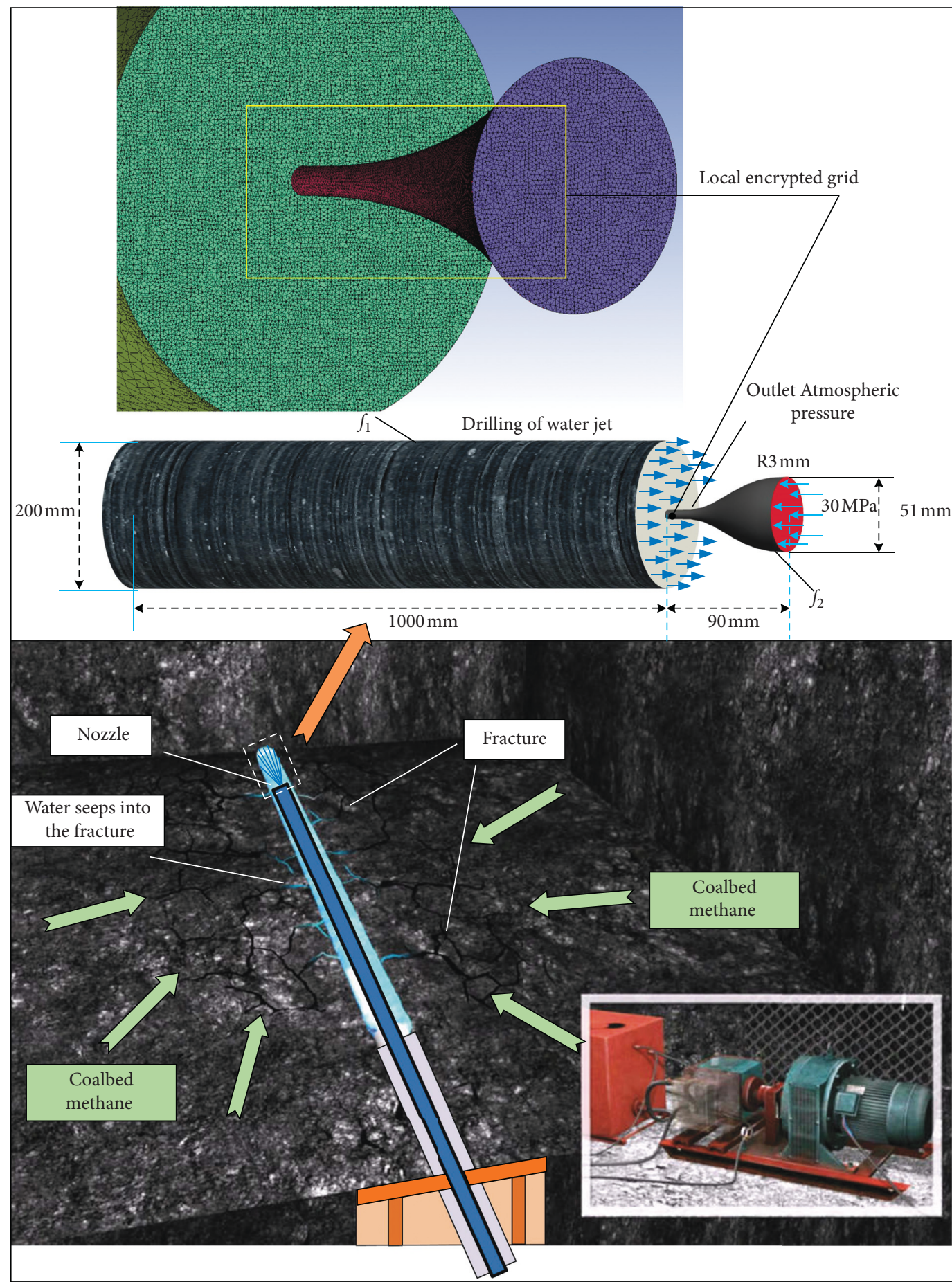

FIgURE 5: Numerical simulation model.

TABle 2: Grid parameter table.

\begin{tabular}{lccc}
\hline Project & $\begin{array}{c}\text { Number } \\
\text { of nodes }\end{array}$ & $\begin{array}{c}\text { Number } \\
\text { of element }\end{array}$ & Tetrahedra \\
\hline Grid model 1 & 341674 & 1690783 & 1690783 \\
Grid model 2 & 170894 & 845743 & 845743 \\
\hline
\end{tabular}

The device solves the problems of small shock-pressure range, small column diameter of jet water, easy to ignore wall resistance, and easy eccentricity of the sensor. The test situation is shown in Figure 8.
During the measurement, the water jet nozzle moved to the pressure measuring board. The measurement of data started is when the distance between the nozzle and the pressure measuring board is 1 meter, and the measurement of data is stopped until the nozzle outlet contacts the pressure measuring board. In the experiment, the water supply pressure is first set to $15 \mathrm{MPa}$. When the equipment had no abnormalities, such as obvious leakage, the pressure is adjusted to $30 \mathrm{MPa}$ for testing. When the pressure is stable, the nozzle starts moving for data measurement. The 

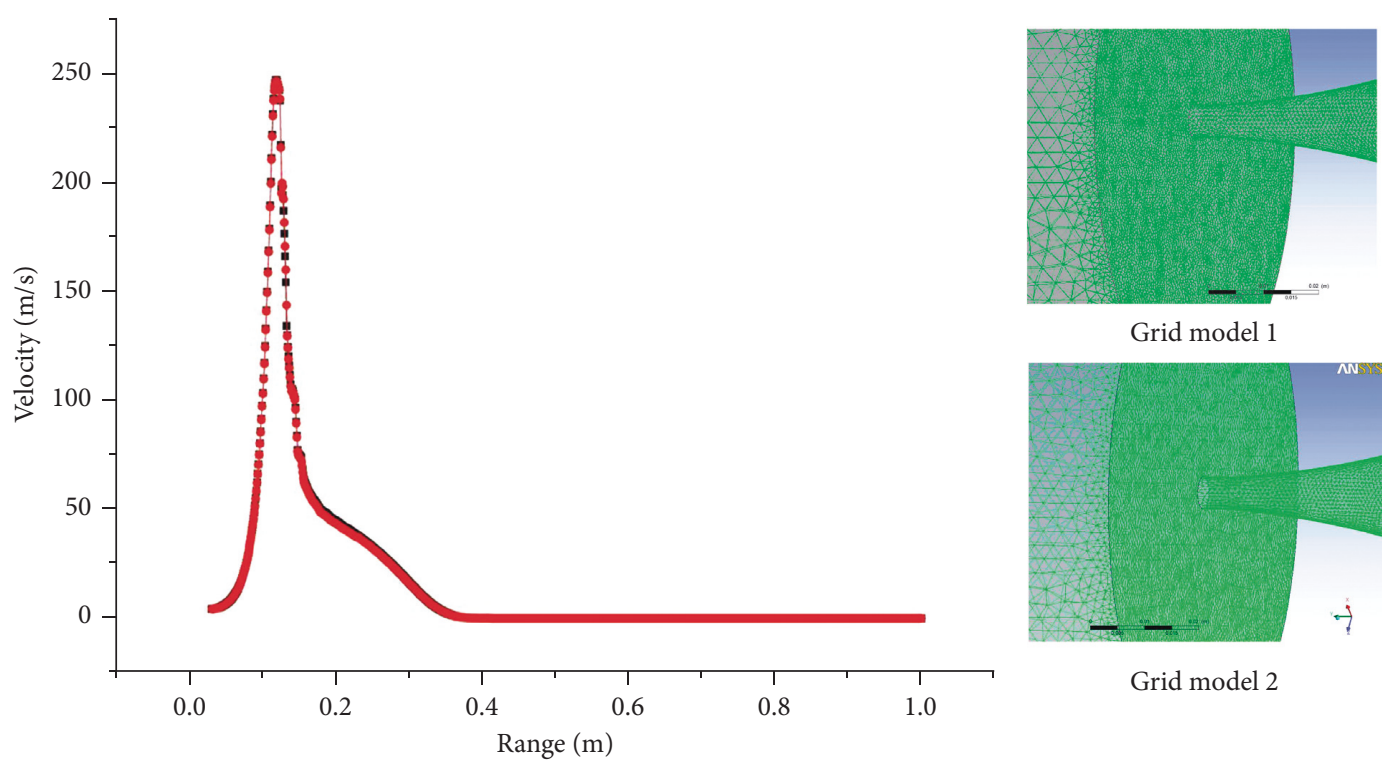

Grid model 1

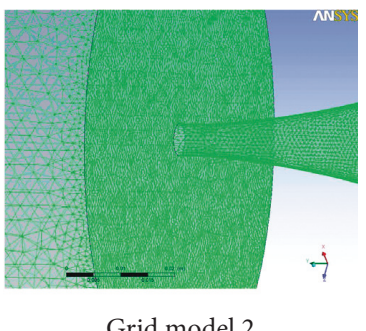

Grid model 2

$\longrightarrow$ Grid model 1

$\rightarrow$ Grid model 2

Figure 6: Grid independence analysis.

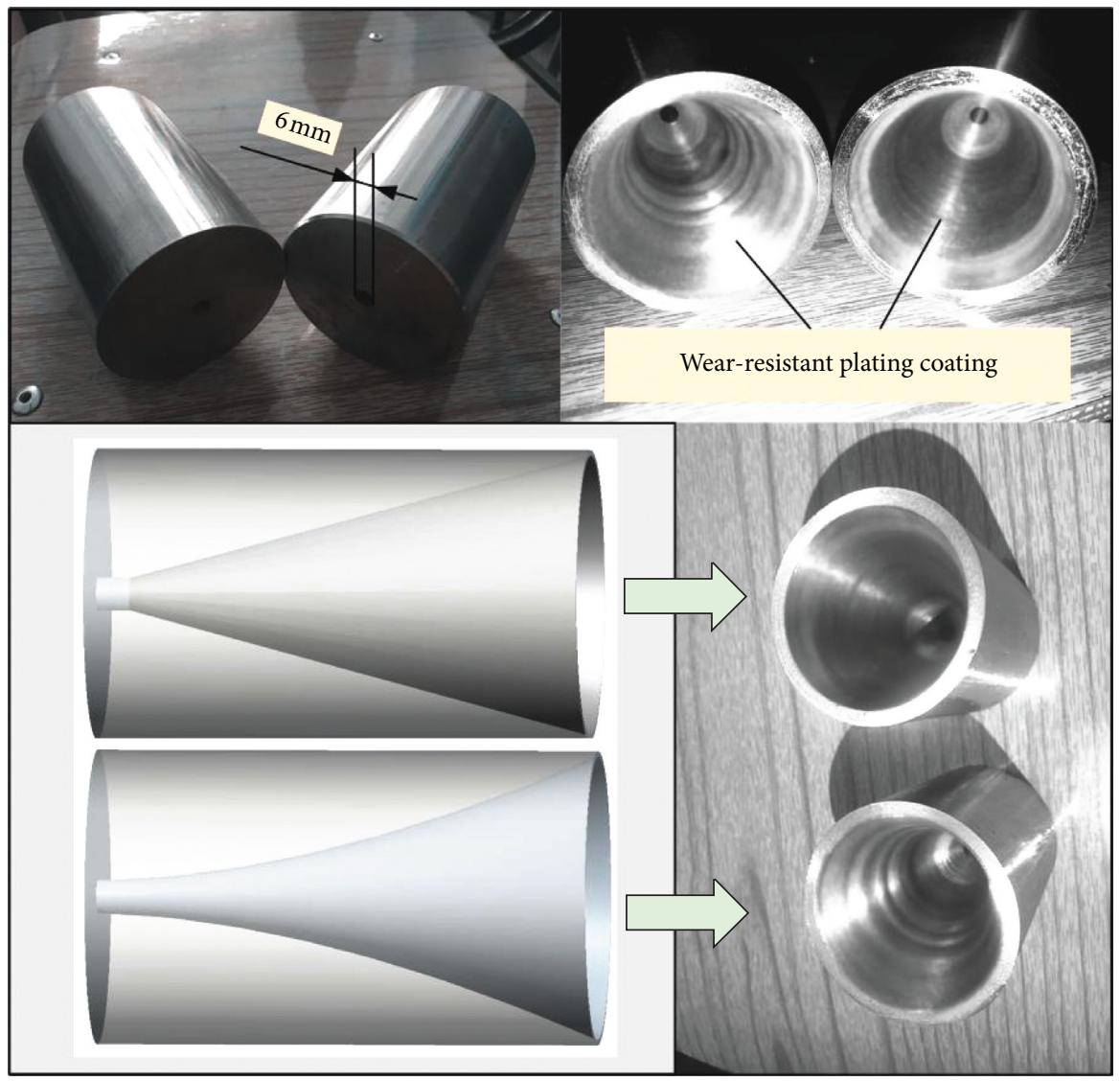

FIgURE 7: Schematic diagram of the nozzle. 
experimental process is exhibited in Figure 8. After completing the measurement, the experimental data of the shock pressure measuring platform are derived and analyzed.

\section{Results and Discussion}

5.1. Simulation Analysis. The results of the four nozzle velocity streamlines are shown in Figure 9.

By analyzing the streamline velocity diagrams of nozzles I, II, III, and IV, the shock of the jet water column on the water body in the borehole can be divided into three regions: shock wave disturbing region, transition region, and slightly disturbed region. In the first region, the streamline velocity of the jet water column gradually decreases, and the diameter of the water column in the core region gradually increases and diverges. The column shears with the surrounding water flow, thereby forming a large reflux. As the shock energy decreases, the water in the transition region does not flow toward the outlet with the return flow, but slowly transfers the energy out in the axial direction. The slightly disturbed region exhibits a small amplitude vibration under the overall shock water pressure, and the flow does not have obvious directionality, thereby indicating that the shock process produces a disturbance wave, and the disturbance wave transmits farther and the distribution is relatively uniform. The nozzle II has a maximum velocity of $247 \mathrm{~m} / \mathrm{s}$ during the entire process. This result shows that the jet water column of nozzle II has the slowest energy decay rate and good energy transfer effect during the entire shock process.

To make the analysis result intuitive and clear, the model is cut along the $X Y$ plane, and the velocity flow field variation law of the incident point of the jet water column that shocks the borehole water body is analyzed, as shown in Figure 10.

The analysis of Figure 10 shows that during the shock process, obvious shock water waves are generated around the jets of nozzles I and III, which is the main way for energy to be transmitted to the surroundings. Therefore, nozzles I and III jet water column divergence is more serious, the energy is more wasteful in the radial transmission, and the longitudinal energy transmission is relatively weakened, thereby resulting in a shorter effective shock range. Although nozzle IV diverges less outside the water column at the exit, the internal velocity of the water column is accelerated in the isokinetic core section. Energy dissipates faster, thereby resulting in a smaller jet shock range. The fluctuation around nozzle II is small, the isokinetic core section of the jet water column is the longest, the shape is full, and the energy velocity decays relatively slowly. Therefore, given the increase in the jet distance, the velocity field of nozzle II's water column highvelocity zone has a slower attenuation and a longer effective shock range, which results in certain advantages.

To determine the velocity streamline trajectory distribution inside the nozzle and when shocking the water body, the velocity vector diagrams of the four nozzles were analyzed, as shown in Figure 11.

Figure 11 is a velocity vector distribution diagram of the jet water column. The velocity direction and size of the fluid at different positions in the four nozzles can be observed. The tail of the velocity vector arrow indicates the position of the analysis point, the length indicates the velocity, and the direction indicates the velocity direction. Therefore, the velocity of the red velocity vector line at the front end of the jet water column is the position of the root of the arrow. The jet water column of nozzle I is concentrated at a position close to the outlet, and then bounces around the periphery, and the velocity is obviously attenuated after the concentrated position. This phenomenon is consistent with the experimental results of Cheng et al. [22]. The jet water column of nozzle I has the smallest velocity vector length along the shock direction. Therefore, the water flow concentration point consumes the most energy. The flow lines of the nozzles II, III, and IV have no obvious intersection, and the main reason for the velocity decay of the jet water column is caused by the shock vortex generated by the flow of the outer water flow to the water column.

The pressure changes of the four nozzle jet water columns are analyzed as shown in Figure 12.

The analysis of Figure 12 indicates that nozzle I produces significant pressure fluctuations at the junction of the rectifying port, the rectifying port, and the nozzle shrinking line. These pressure fluctuations are caused by eddy currents caused by the unbalanced processing relationship between the nozzle rectifying effect and the wall resistance. Nozzle II produces a small eddy current at a position closer to the outlet, and the number and amplitude are small. The relationship between the rectifying effect and the wall resistance of nozzle II is relatively close to equilibrium. The number of eddy currents generated by nozzles III and IV near the wall near the outlet is large and the range is large. The near-wall eddy currents are the source of the radial transfer of pressure at the center of the accelerated jet.

We analyze the relationship between the number and range of small pressure waves on the near wall and the divergence of jet-water-column pressure. Nozzle IV generates the largest number of pressure fluctuations along the wall surface and the largest range, thereby causing the jet water column to propagate radially in the radial direction and decay fastest in the axial direction. The number of pressure fluctuations generated by nozzle II along the wall surface is the smallest and the range is the smallest. The shape of the high-pressure area of the jet water column is full, and the velocity spreads the slowest along the radial direction and decays the slowest along the axial direction. The rectifying and drag reducing effect of the nozzle is the best. Therefore, the pressure fluctuation generated in the near-wall region near the nozzle is an important factor that affects the pressure transmission form of the jet water column. The greater the number of pressure fluctuations, the larger the range, and the faster the axial pressure decay of the jet water column. However, the pressure decay is also related to the rectification situation. The number of pressure fluctuations generated by nozzle I is also large, but the pressure distribution at the front end of the jet water column is also relatively full because the water column of nozzle I will be concentrated at the front end of the nozzle. This situation slows down the pressure drop of the water column between 


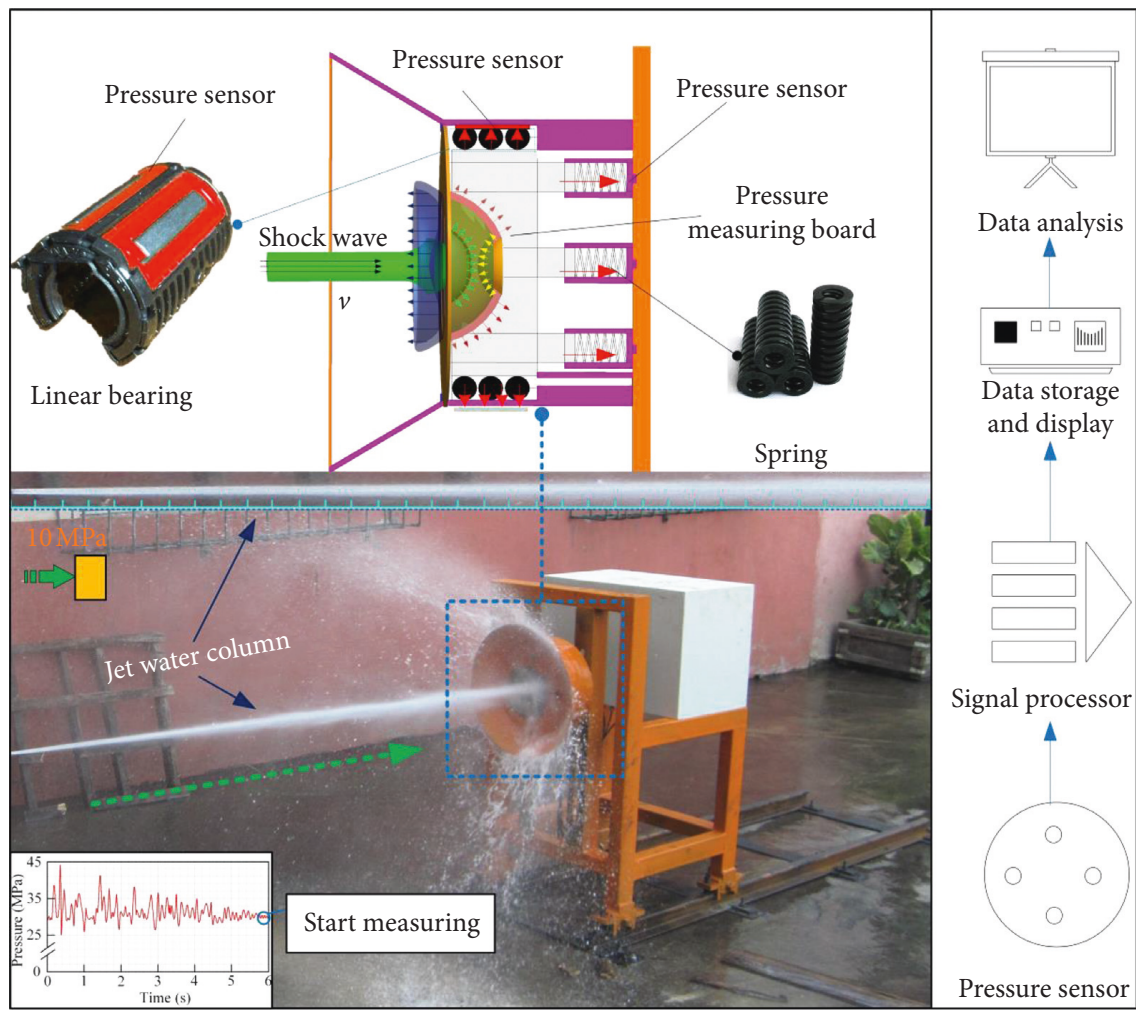

FIgURE 8: Experimental diagram of shock-pressure measurement.

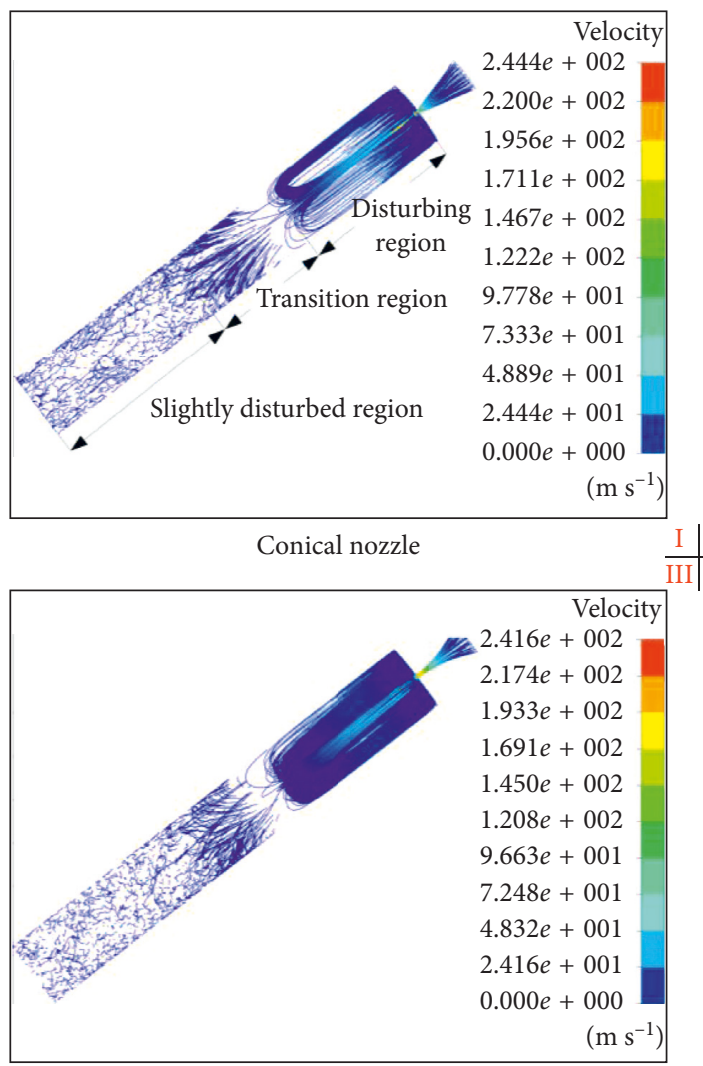

Fat-type streamlined nozzle

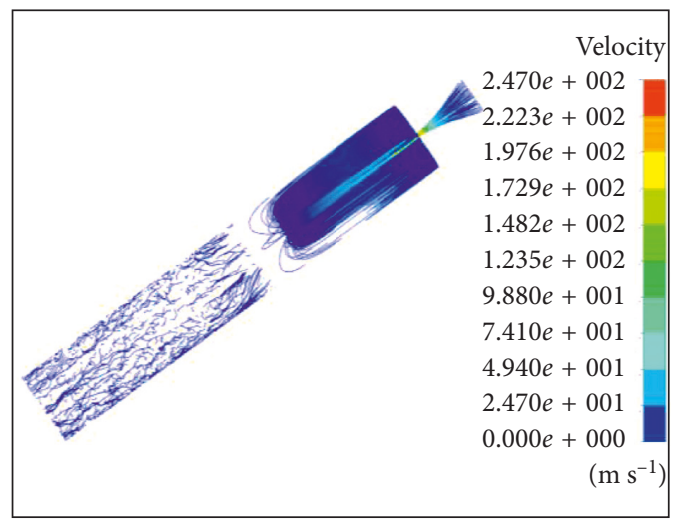

Thin-type streamlined nozzle

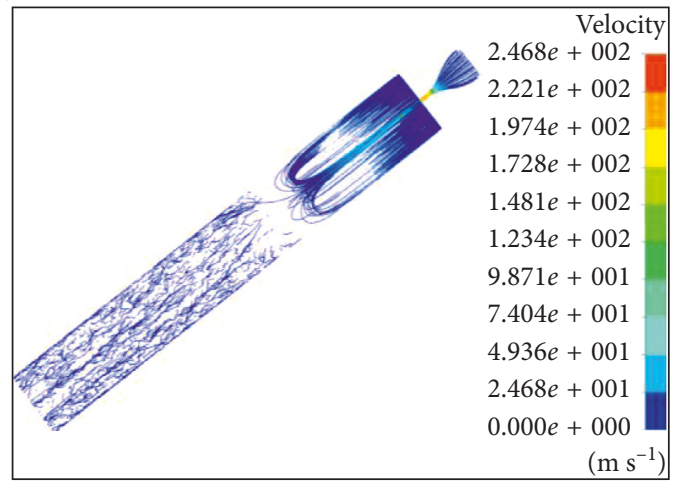

Double-chamfered streamlined nozzle

FIGURE 9: Jet water column velocity streamline diagram. 


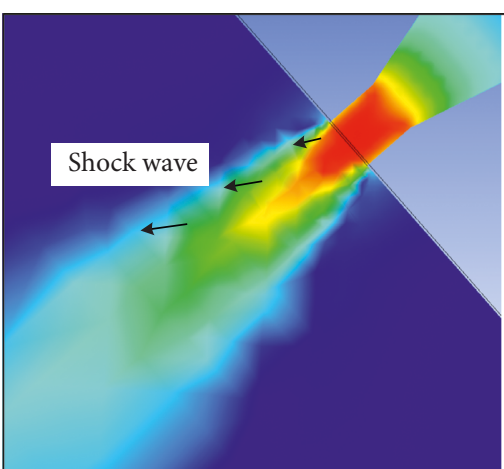

Conical nozzle

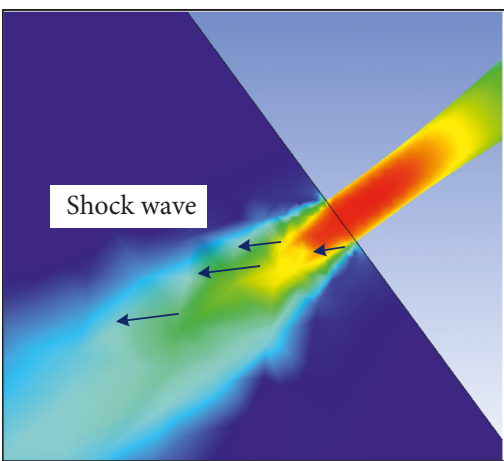

Fat-type streamlined nozzle

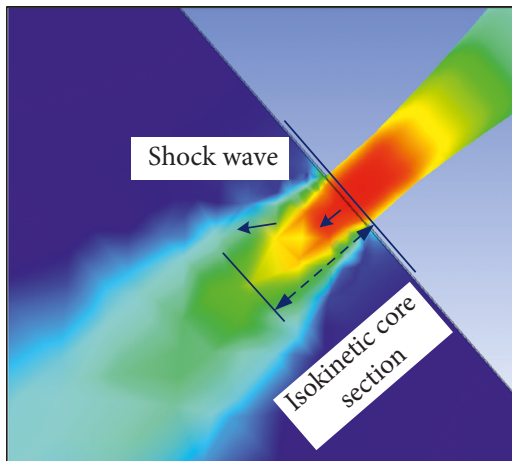

$2.470 e+002$

$2.223 e+002$

$1.976 e+002$

$1.729 e+002$

$1.482 e+002$

$1.235 e+002$

$9.880 e+001$

$7.410 e+001$

$4.940 e+001$

$2.470 e+001$

$0.000 e+000$ $\left(\mathrm{m} \mathrm{s}^{-1}\right)$

\begin{tabular}{l|l} 
I & II \\
\hline III & IV
\end{tabular}

Velocity
$2.416 e+002$
$2.174 e+002$
$1.933 e+002$
$1.691 e+002$
$1.450 e+002$
$1.208 e+002$
$9.663 e+001$
$7.248 e+001$
$4.832 e+001$
$2.416 e+001$
$0.000 e+000$
$\quad\left(\mathrm{~m} \mathrm{~s}^{-1}\right)$

$\left(\mathrm{m} \mathrm{s}^{-1}\right)$

Figure 10: Velocity field distribution diagram of jet water column.

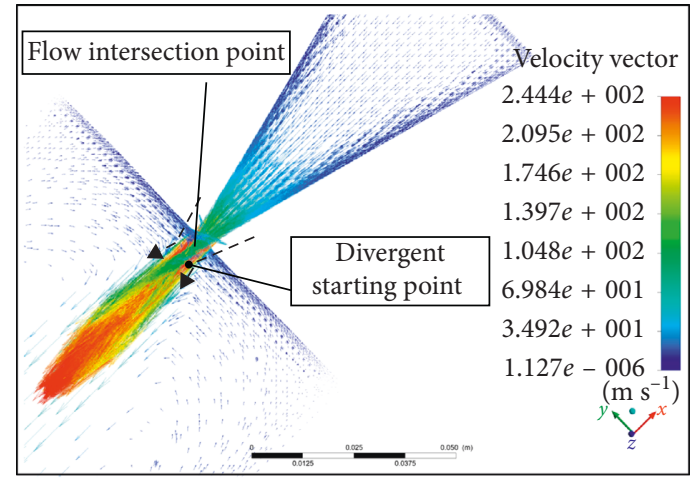

Conical nozzle

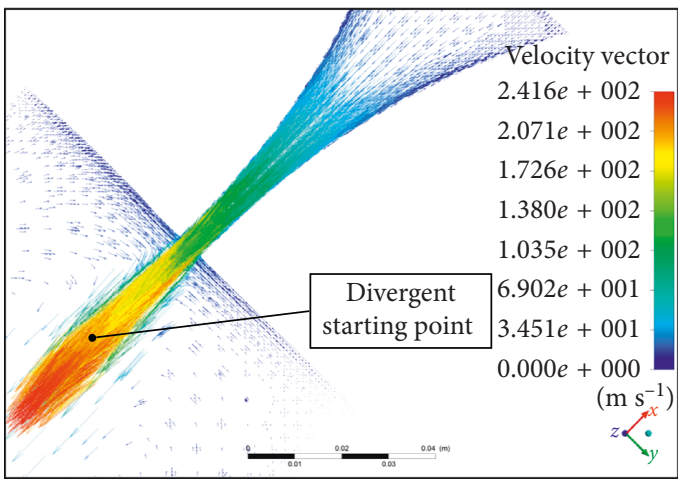

Fat-type streamlined nozzle

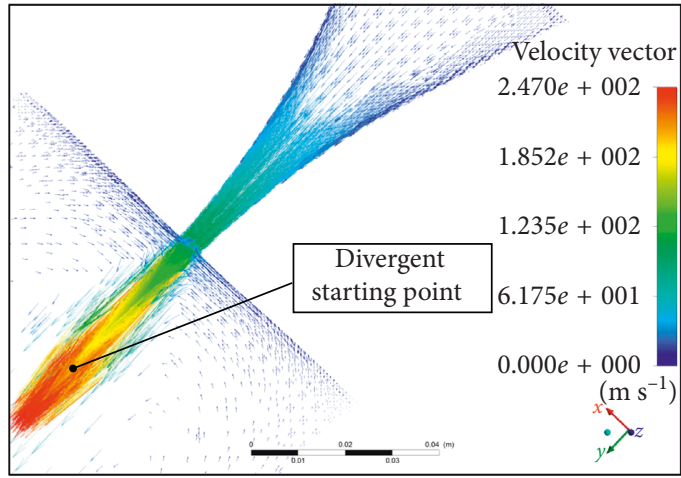

Thin-type streamlined nozzle

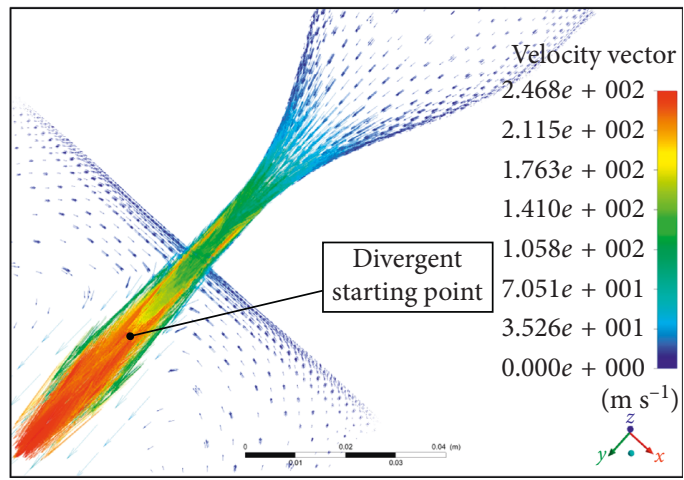

Double-chamfered streamlined nozzle

FIGURE 11: Jet water column velocity vector distribution. 

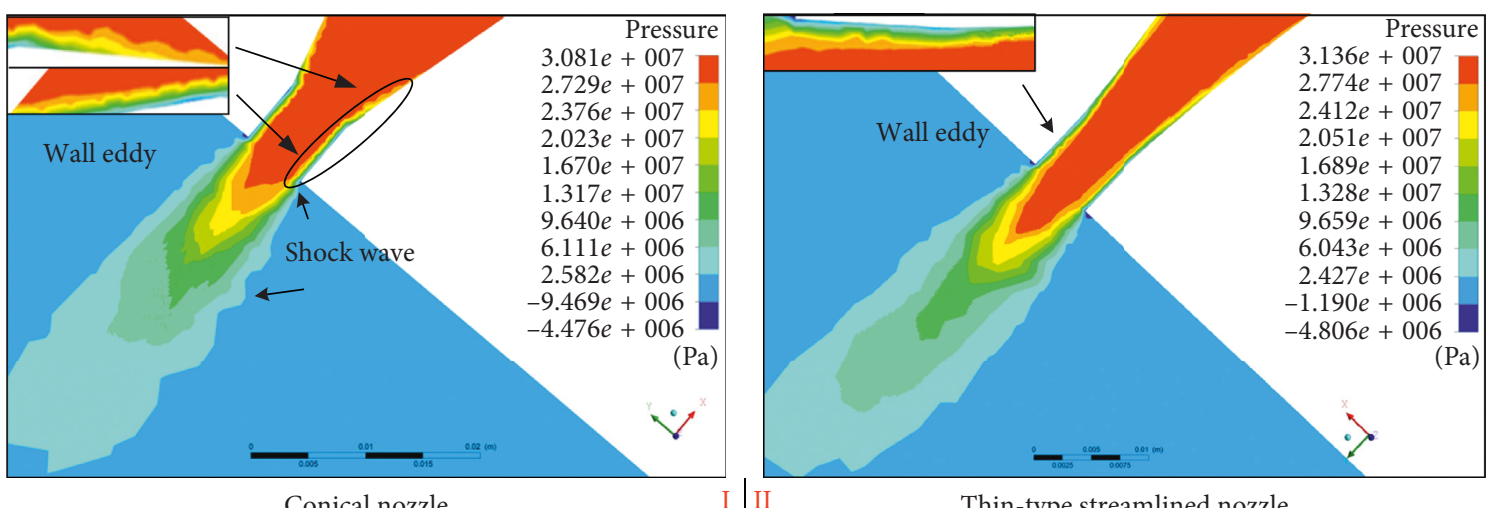
\begin{tabular}{l|l} 
I & II \\
\hline III & IV \\
\hline
\end{tabular}

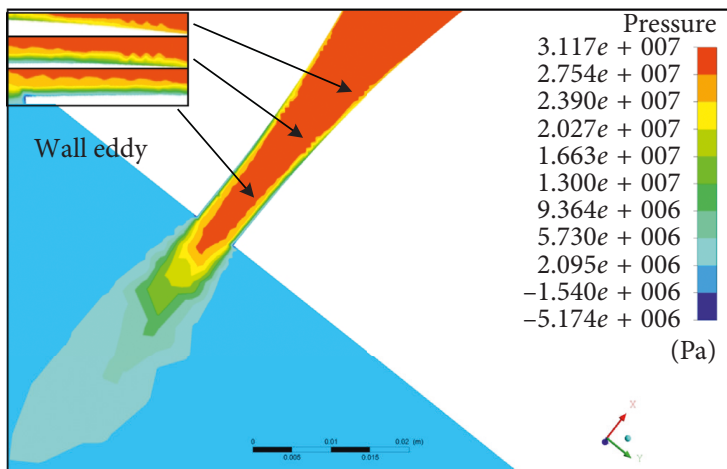

Fat-type streamlined nozzle

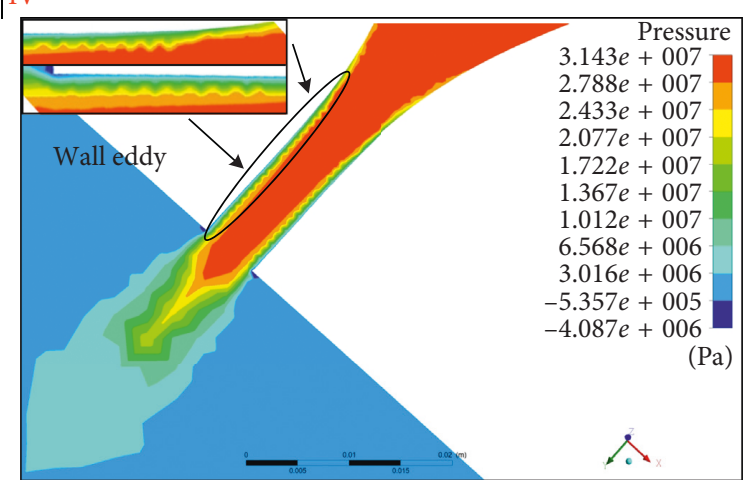

Double-chamfered streamlined nozzle

Figure 12: Jet-water-column pressure distribution map.

the concentration point and the nozzle, and a large attenuation occurs after the concentration point. Therefore, the rectification effect of the nozzle and the small-pressure fluctuation of the near-wall surface jointly affect the pressure variation pattern of the jet water column.

To study quantitatively the velocity decay law of the four nozzle jets, the velocity at the midline position, which is the most representative of the jet water velocity attenuation, is analyzed as shown in Figure 13.

Figure 13 is a graph that shows the velocity variation of the central axis from the nozzle inlet to the end of the jet water column. The velocity on the central axis is the most representative of the attenuation trend of the jet water column; thus, it is analyzed. The velocity increase area is mainly the inner area of the nozzle, and the velocity is accelerated within an extremely short distance outside the nozzle. Analysis of the four nozzle velocity change diagrams shows that the center velocity of nozzle II is $247 \mathrm{~m} / \mathrm{s}$ at the exit; thus, the internal drag reduction effect of nozzle II is the best. After water ejection, the center velocity of the water column is rapidly attenuated, the fastest decaying velocity is nozzle IV, and the slowest decaying velocity is nozzle II, thereby indicating that nozzle II has improved divergence control for the water column.

The above analysis indicates that when nozzle II shocks the water body, the isokinetic core section is the fullest, the velocity decays the slowest along the axial direction, the pressure decays the slowest along the axial direction, the highpressure zone has the lowest radial energy transfer, and the nozzle interior rectification and drag are optimal. Therefore, nozzle II was selected as the best streamlined nozzle.

5.2. Analysis of Experimental Results. The literature [23] and the empirical formula of on-site punching and breaking coal indicate that the relationship between $P_{\mathrm{c}}$ and $f_{\mathrm{c}}$ is determined as $P_{\mathrm{c}}=10 f_{\mathrm{c}}$, where $P_{\mathrm{c}}$ is the coal-breaking pressure and $f_{\mathrm{c}}$ is the hardness coefficient of coal. In our experimental study of a coal seam, we investigated is the Qianjiaying coalmine of Kailuan Group. The coal $f_{\mathrm{c}}$ value is 0.6. Therefore, the empirical coal-breaking pressure is $6 \mathrm{MPa}$, and the selected reference plane is $P_{c}=6 \mathrm{MPa}$. The distance between the highpressure water-jet punching angle adjustment position and the nozzle exit position is $300 \mathrm{~mm}$. The punching angle adjustment range is $0^{\circ}-30^{\circ}$. The change trend in shock pressure of the two nozzles is shown in Figure 14. The analysis found that the shock pressure of the two sets of nozzles gradually increased with the increase of the shock range in the area closer to the nozzle. The shock pressure at the nozzle exit is not maximum, and the ejected water column undergoes an acceleration process in the air. Then, the shock pressure fluctuated significantly, the shock pressure was significantly attenuated with the increase of the range, and the fluctuation range was also significantly reduced.

The maximum shock pressure of the two nozzles is not considerably different. However, the shock pressure of nozzle II is longer in the high-pressure zone, and the coalbreaking efficiency is higher. The shock pressure of nozzle 


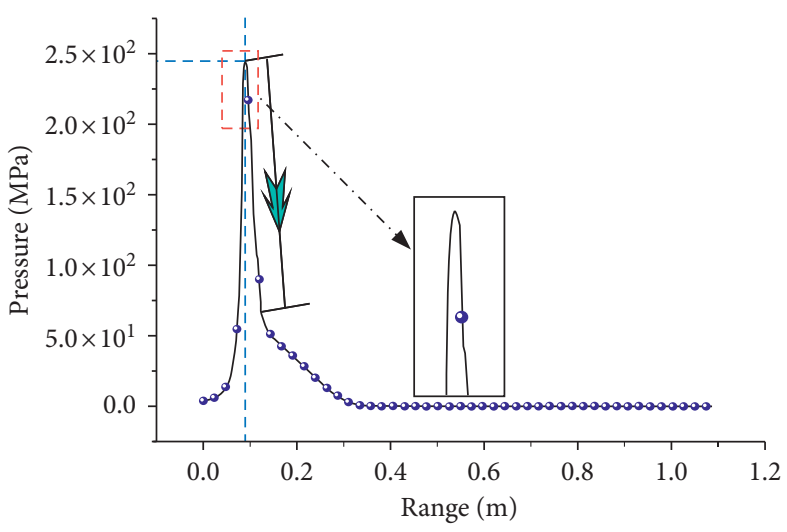

$\multimap-$ Ordinary conical nozzle

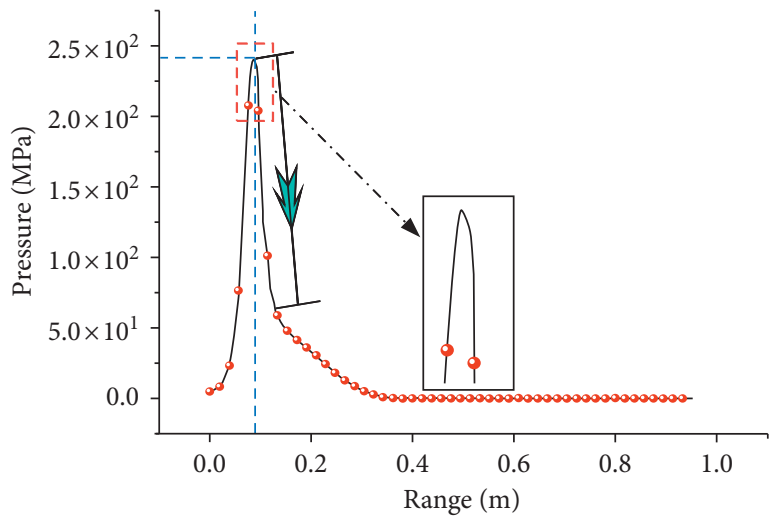

-o- Fat-type streamlined nozzle

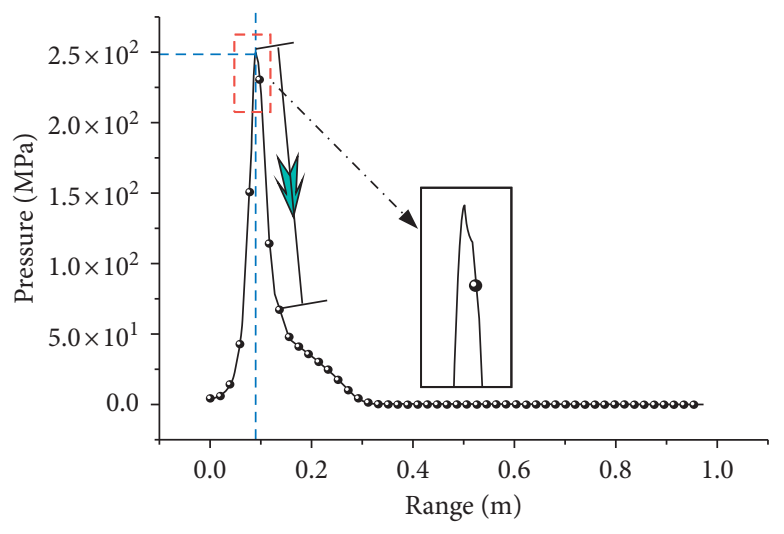

- Thin-type streamlined nozzle

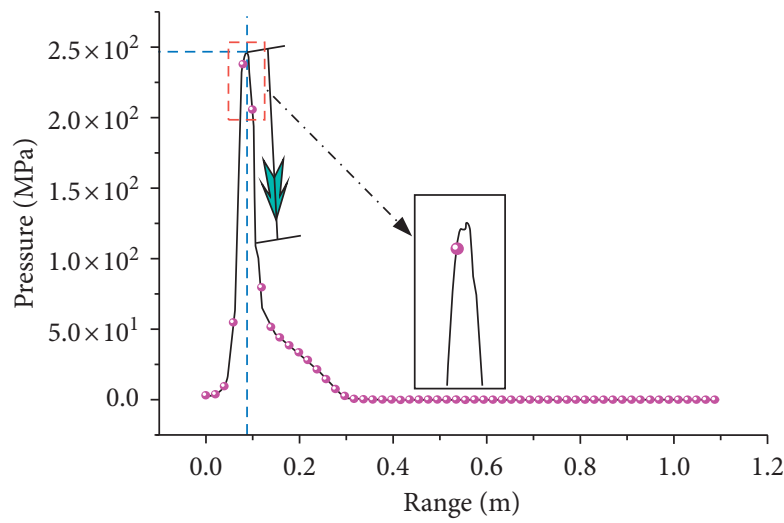

-๑- Double-chamfered streamlined nozzle

FIgURe 13: Flow diagram of jet flow velocity change analysis.

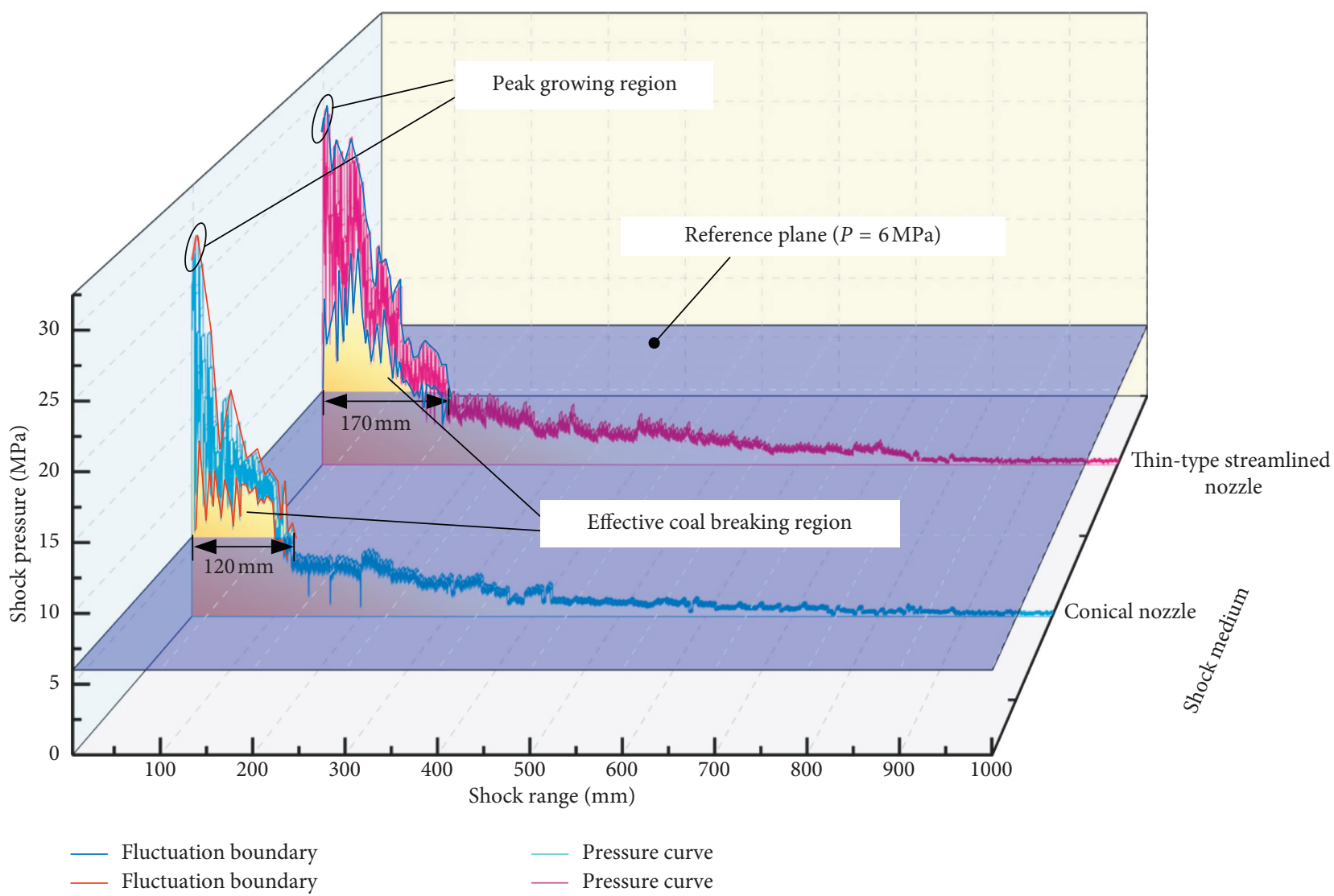

Figure 14: Experimental data analysis chart. 


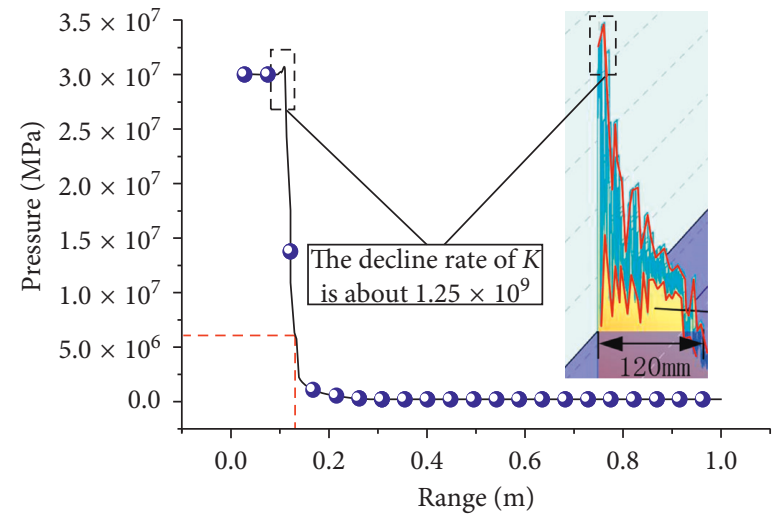

- - Ordinary conical nozzle

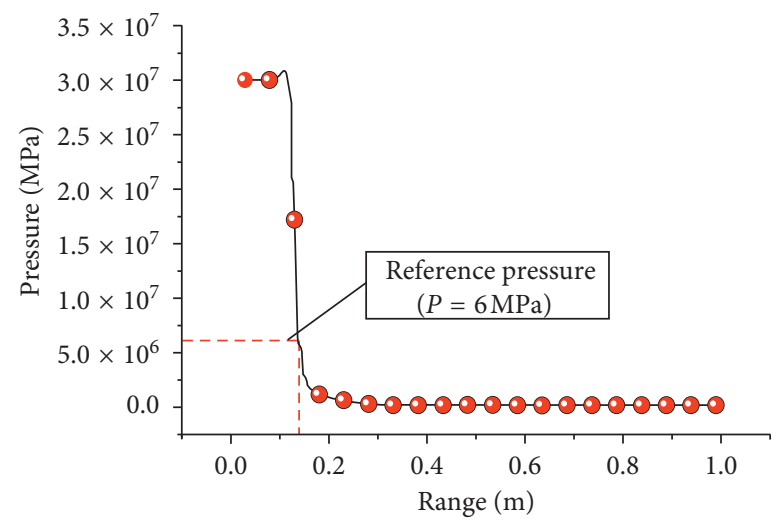

- - Fat-type streamlined nozzle

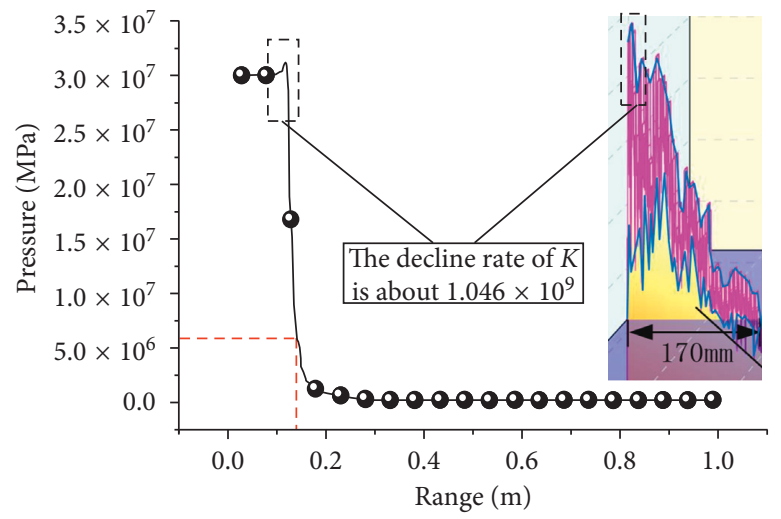

- Thin-type streamlined nozzle

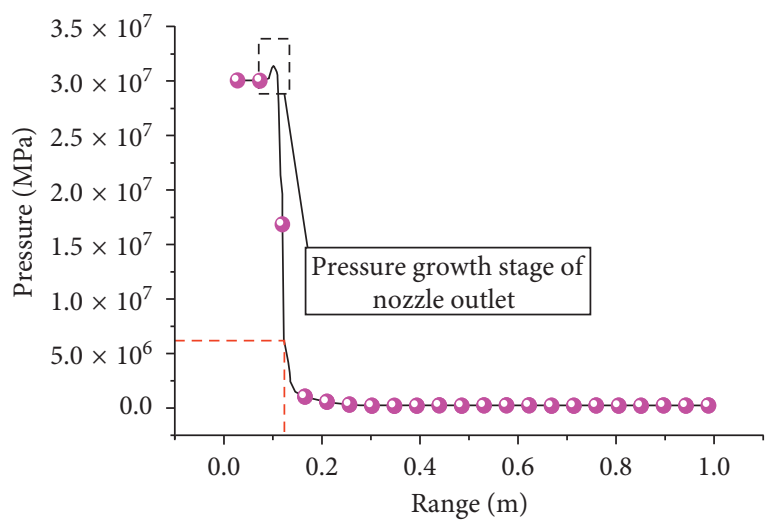

-o- Double-chamfered streamlined nozzle

FIgURE 15: Comparison of numerical simulation and experiment.

I is greater than $6 \mathrm{MPa}$ in the range of $120 \mathrm{~mm}$ from the nozzle, and this range is an effective coal-breaking water column. The effective length of the jet stream of nozzle II is $170 \mathrm{~mm}$, and the effective shock breaking distance is increased by $50 \mathrm{~mm}$. The effective breaking distance of nozzle II is 1.417 times that of the jet water column of nozzle I. When punching, the maximum hole expansion angle of the punching device is $30^{\circ}$, the maximum punching hole diameter of nozzle I is $R_{\mathrm{c}}=139.752 \mathrm{~mm}$, and the maximum punching hole diameter of nozzle II is $R_{t}=165.632 \mathrm{~mm}$. The reaming radius is 1.19 times that of nozzle I. The crosssectional area of nozzle I is $61302.4575 \mathrm{~mm}^{2}$, the crosssectional area of nozzle II is $86142.6326 \mathrm{~mm}^{2}$, the reaming area is enlarged by $24840.1751 \mathrm{~mm}^{2}$, and the aperture section of nozzle II is 1.405 times that of nozzle I. In summary, nozzle II has high coal-breaking efficiency, large effective coal-breaking distance, largest punching area, maximum surrounding rock disturbance, widest crack development, and best permeability enhancement effect, thereby helping to improve CBM drainage efficiency. Therefore, nozzle II is more suitable for quick and efficient punching and penetrating operations.

5.3. Comparative Analysis of Simulation and Experiment. To verify the correctness of the analytical simulation and experiment, the water pressure center position pressure and the measured shock-pressure data were compared and analyzed. The pressure at the center is the maximum pressure of the section, and the peak value of the measured shock pressure is the maximum pressure at a certain position. Thus, the two trends can be comparatively analyzed. The simulation study is the process of jet water column shocking water. In measuring the shock pressure, when the nozzle is close to the pressure measuring sensor, a considerable amount of water is generated due to the action of the water hammer and the shock process, such that the nozzle and the pressure measuring plate are filled with water. The measured pressure is the pressure of the shock water column in the water body. Therefore, the data are comparable at a position close to the nozzle, which is shown in Figure 15.

The analysis of Figure 15 shows that the shock results of the conical nozzle shock pressure and the field measurement results appear to increase and then decay rapidly. The trend is the same, and the attenuation rate is close to $1.25 \times 109 \mathrm{~Pa} / \mathrm{m}$. The shock-pressure simulation results of nozzle II and the field measurement results showed a phenomenon of rapid increase and then rapid decay. The trend was the same, and the attenuation rates were close to $1.046 \times 109 \mathrm{~Pa} / \mathrm{m}$. Therefore, the experimental results are consistent with the simulation results. The effective shock range of nozzle I in water is $40 \mathrm{~mm}$, the effective shock range of nozzle II is $52 \mathrm{~mm}$, and the reaming radii are $98.344 \mathrm{~mm}$ and $104.5552 \mathrm{~mm}$, respectively. The reaming 
radius is 1.06 times. The effective shock ranges in air are 120 and $170 \mathrm{~mm}$, respectively. Therefore, we recommend taking intermittent impulses in the punching process, increasing the drilling angle, improving the drainage efficiency, and reducing the resistance of the jet water column before breaking coal, thereby improving the working efficiency.

\section{Conclusion}

After theoretical analysis, we determined that optimizing the internal streamline structure of the nozzle, reducing the internal resistance of the nozzle, and improving the rectification effect are essential to improving the shock damage capability of the high-pressure water jet.

Among the three streamlined nozzles designed with reference airfoil curves, the thin-type streamlined nozzle (nozzle II) has the best rectification and drag reduction effect, which not only reduces the water column divergence rate but also reduces the energy loss. The isokinetic core section of the jet water column is the longest and most full, and the shock energy is transmitted the furthest along the axial direction, which is selected as the theoretical optimal nozzle. The small-pressure fluctuation on the near wall and the rectification effect of the nozzle jointly affect the pressure change pattern of the jet water column. The greater the number of pressure fluctuations and the larger the range, the faster the pressure is attenuated toward the center of the water column after ejection, and the shorter the axial pressure propagation distance. The concentration of water flow caused by rectification will slow down the attenuation of the jet-water-column pressure between the concentration point and the nozzle but will accelerate the attenuation of the jet-water-column pressure after the concentration point.

The shock-pressure measurement experiment shows that the maximum peak pressure of the high-pressure water jet is not far from the nozzle after the ejection. The water column undergoes an acceleration process in the air. In the range of effective coal-breaking pressure, the shock pressure of nozzle II is relatively slow, the distance is long in the high shockpressure region, and the coal-breaking efficiency is high. The effective breaking distance of nozzle II is 1.185 times that of the conical nozzle (nozzle I) jet water column, the hole expansion area is expanded by $24840.1751 \mathrm{~mm}^{2}$, and the aperture section of nozzle II is 1.405 times that of nozzle I. The reaming area is large, the surrounding rock disturbance is the largest, the crack is the most widely developed, the permeability enhancement effect is the best, and the CBM drainage effect is improved.

\section{Nomenclature}

$\begin{array}{ll}A_{n}: & \text { Area of section } \mathrm{A}_{n}-\mathrm{A}_{n} \\ E\left(u_{\mathrm{c}}\right): & \text { Kinetic energy at the inlet of the nozzle } \\ u_{n}: & \text { Velocity distribution on section } \mathrm{A}_{n}-\mathrm{A}_{n} \\ E\left(u_{0}\right): & \text { Kinetic energy at the outlet of the nozzle } \\ u_{0}: & \text { Nozzle exit center line velocity } w \\ F(x): & \text { Streamline body curve function } \\ R_{0}: & \text { Nozzle outlet radius }\end{array}$

$H(x)$ : Compound function

$R_{\mathrm{m}}$ : $\quad$ Radius of the plane $\mathrm{m}$

$y_{\text {up }}, y_{\text {low: }}$ Vertical coordinates of the upper, lower surfaces of the airfoil, respectively

$u_{m}: \quad$ Velocity of the plane distribution of the $m$

$s_{0}$ : $\quad$ Length of the isokinetic core section of a jet water column

$y_{\text {up0 }}, y_{\text {low0 }}$ : Vertical coordinates of the upper, lower surfaces of the base airfoil, respectively

$f: \quad$ Internal wall resistance of the nozzle

$k, m$ : Number, coefficient of the parameters to control

the shape of the airfoil, respectively

$\theta$ : $\quad$ Divergence angle

$\mu_{t}$ : Turbulent viscosity

$k_{1}, k_{2}$ : Scaling coefficient of the $X$ axis, $Y$ axis, respectively

$u_{i}: \quad$ Time average velocity

$\rho: \quad$ Density

$S_{k}, S_{\varepsilon}: \quad$ User-defined source items

$u^{+}: \quad$ Near-wall velocity

$C_{1 \varepsilon}, C_{2 \varepsilon}, \quad$ Empirical constants

$C_{3 \varepsilon}$ :

K: $\quad$ Karman constant

$F_{f}$ Rolling friction

$y^{R}: \quad$ Roughness

$S: \quad$ Area of jet water column cross-sectional

$\mu$ : Molecular viscosity

$F: \quad$ Shock force

$F_{1}$ : $\quad$ Spring transfer pressure

$P: \quad$ Shock pressure

$C$ : $\quad$ Basically rated as the dynamic load

$F_{2}$ : $\quad$ Loading outside the bearing

$G_{k}$ : Generation term of the turbulent kinetic energy

due to the average velocity gradient

$y^{*}$ : $\quad$ Conjugate function with a dimensionless $k$

distance to the wall

$R_{\mathrm{t}}: \quad$ Nozzle II punching radius

$R_{\mathrm{c}}$ : $\quad$ Nozzle I punching radius.

\section{Data Availability}

The data used to support the findings of this study are available from the corresponding author upon request.

\section{Conflicts of Interest}

The authors declare that they have no conflicts of interest.

\section{References}

[1] I. Palmer, "Coalbed methane wells are cheap, but permeability can be expensive," Energy Tribune, vol. 3, pp. 10-13, 2008.

[2] G. Wang, W. Li, P. Wang, X. Yang, and S. Zhang, "Deformation and gas flow characteristics of coal-like materials under triaxial stress conditions," International Journal of Rock Mechanics and Mining Sciences, vol. 91, pp. 72-80, 2017.

[3] F. Chaojun, L. Sheng, and L. Mingkun, "Deep CBM extraction numerical simulation based on hydraulic-mechanicalthermal coupled model," Journal of China Coal Society, vol. 41, no. 12, pp. 3076-3085, 2016. 
[4] G. Wang, M. Wu, R. Wang, H. Xu, and X. Song, "Height of the mining-induced fractured zone above a coal face," Engineering Geology, vol. 216, pp. 140-152, 2017.

[5] G. Wang, P. Wang, Y. Guo, and W. Li, "A novel true triaxial apparatus for testing shear seepage in gas-solid coupling coal," Geofluids, vol. 2018, Article ID 2608435, 9 pages, 2018.

[6] J. Seidle, Fundamentals of Coalbed Methane Reservoir Engineering, PennWell Books, Houston, TX, USA, 2011.

[7] X. Liu, S. Liu, and H. Ji, "Numerical research on rock breaking performance of water jet based on SPH," Powder Technology, vol. 286, pp. 181-192, 2015.

[8] J. Schwartzentruber and M. Papini, "Abrasive waterjet micropiercing of borosilicate glass," Journal of Materials Processing Technology, vol. 219, pp. 143-154, 2015.

[9] M. Lieblich, S. Barriuso, J. Ibáñez et al., "On the fatigue behavior of medical Ti6Al4V roughened by grit blasting and abrasiveless waterjet peening," Journal of the Mechanical Behavior of Biomedical Materials, vol. 63, pp. 390-398, 2016.

[10] K. Balamurugan, M. Uthayakumar, S. Gowthaman, and R. Pandurangan, "A study on the compressive residual stress due to waterjet cavitation peening," Engineering Failure Analysis, vol. 92, pp. 268-277, 2018.

[11] X.-h. Li, D.-p. Zhou, Y.-y. Lu, Y. Kang, Y. Zhao, and X.-c. Wang, "Dynamic effects of high-pressure pulsed water jet in low-permeability coal seams," Journal of Coal Science and Engineering (China), vol. 15, no. 3, pp. 284-288, 2009.

[12] J. Schwartzentruber, J. Spelt, and M. Papini, "Modelling of delamination due to hydraulic shock when piercing anisotropic carbon-fiber laminates using an abrasive waterjet," International Journal of Machine Tools and Manufacture, vol. 132, pp. 81-95, 2018.

[13] N. Baisheng, W. Hui, L. Lei et al., "Numerical investigation of the flow field inside and outside high-pressure abrasive waterjet nozzle," Procedia Engineering, vol. 26, pp. 48-55, 2011.

[14] D. Li, Y. Kang, X. Ding, X. Wang, and Z. Fang, "Effects of area discontinuity at nozzle inlet on the characteristics of high speed self-excited oscillation pulsed waterjets," Experimental Thermal and Fluid Science, vol. 79, pp. 254-265, 2016.

[15] N. Fujisawa, Y. Fujita, K. Yanagisawa, K. Fujisawa, and T. Yamagata, "Simultaneous observation of cavitation collapse and shock wave formation in cavitating jet," Experimental Thermal and Fluid Science, vol. 94, pp. 159-167, 2018.

[16] C. Peng, S. Tian, and G. Li, "Joint experiments of cavitation jet: high-speed visualization and erosion test," Ocean Engineering, vol. 149, pp. 1-13, 2018.

[17] G. G. Pereira, P. W. Cleary, and Y. Serizawa, "Prediction of fluid flow through and jet formation from a high pressure nozzle using Smoothed Particle Hydrodynamics," Chemical Engineering Science, vol. 178, pp. 12-26, 2018.

[18] B.-q. Lin, T. Liu, Y. Zhou, Z. Zhang, and F.-z. Yan, "Variation of methane adsorption property of coal after the treatment of hydraulic slotting and methane pre-drainage: a case study," Journal of Natural Gas Science and Engineering, vol. 20, pp. 396-406, 2014.

[19] A. Momber, "Image processing as a tool for high-pressure water jet coating removal assessment," International Journal of Advanced Manufacturing Technology, vol. 87, no. 1-4, pp. 571-578, 2016.

[20] P. S. Granville, "Geometrical characteristics of streamlined shapes," Journal of Ship Research, vol. 13, no. 4, pp. 299-313, 1969.

[21] J. Chen, L.-w. Guo, J.-g. Wu, L.-h. Guan, and F.-z. Li, "Experimental study on tip diameters and punching angles of high pressure water jet," Safety in Coal Mines, vol. 47, no. 5, pp. 1-5, 2016, http://nvsm.cnki.net/kns/brief/default_result. aspx.

[22] F. Cheng, W. Ji, C. Qian, and J. Xu, "Cavitation bubbles dynamics and cavitation erosion in water jet," Results in Physics, vol. 9, pp. 1585-1593, 2018.

[23] Z. Pan and L. D. Connell, "A theoretical model for gas adsorption-induced coal swelling," International Journal of Coal Geology, vol. 69, no. 4, pp. 243-252, 2007. 


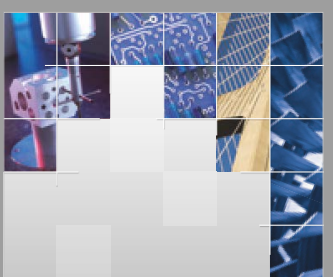

\section{Enfincering}
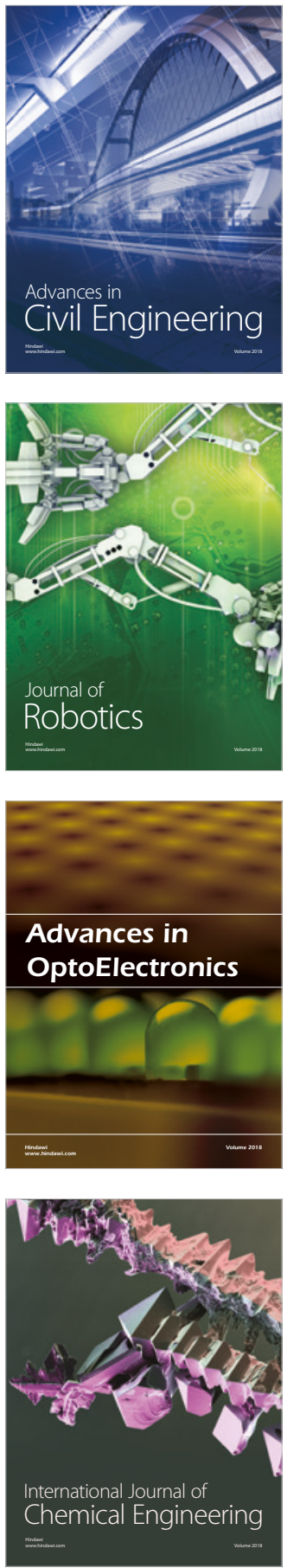

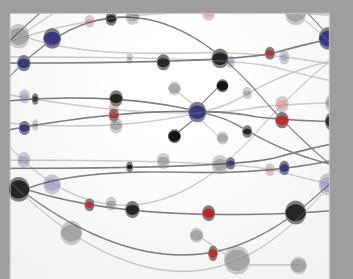

\section{Rotating \\ Machinery}

The Scientific World Journal

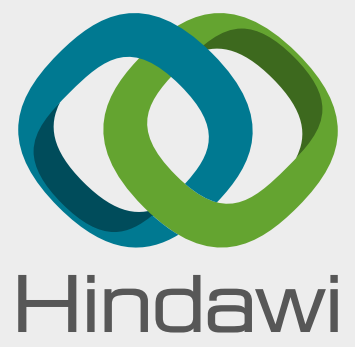

Submit your manuscripts at

www.hindawi.com
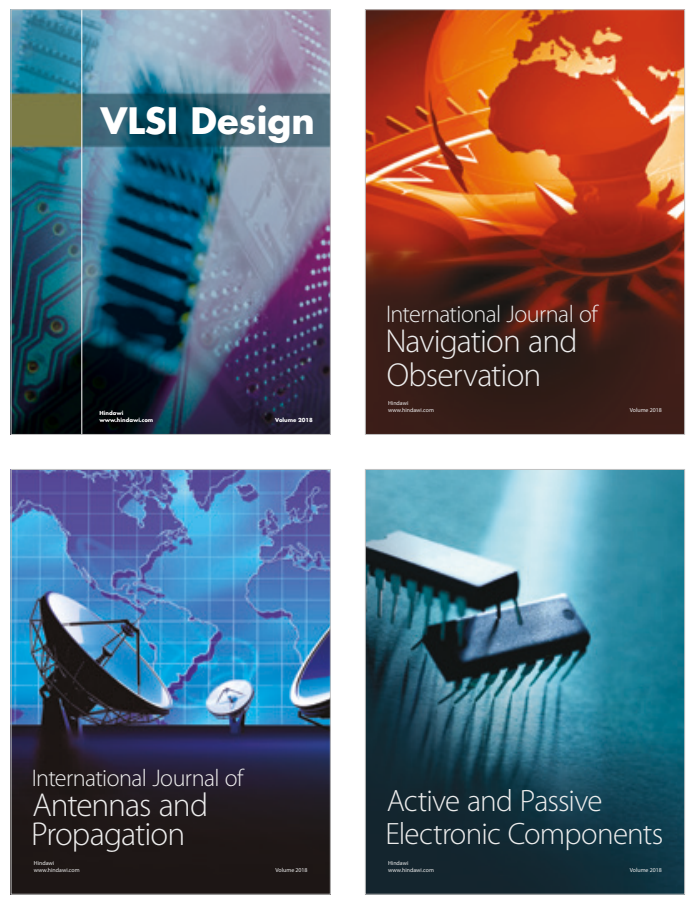
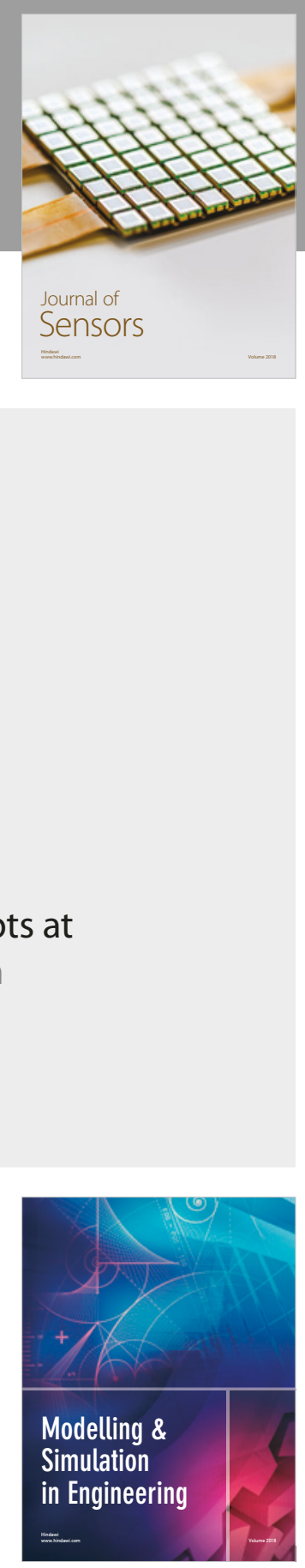

\section{Advances \\ Multimedia}
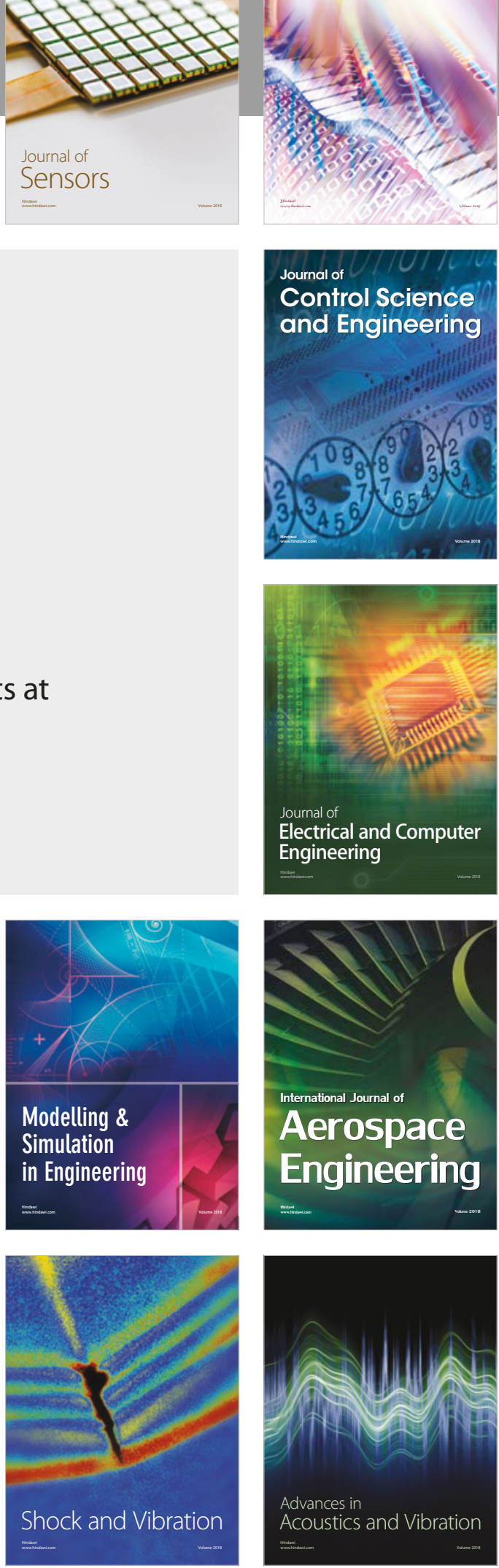